\title{
CAMPESINOS Y TENENCIA DE LA TIERRA EN EL ALTIPLANO PERUANO EN LA TRANSICIÓN DE LA COLONIA A LA REPÚBLICA
}

Nils Jacobsen

LA PRINCIPAL PARADOJA del régimen de tenencia de la tierra en el norte del Altiplano durante la última parte del período colonial fue la siguiente: la tierra era barata. Todavía no se había convertido en un "bien mercancía", ya que en principio era comercializada como una parte secundaria del capital de ganado al cual alimentaba. En la mayoría de las transacciones el valor del ganado y el de sus pastos era uno solo. Sin el ganado los pastos valían muy poco. Esto correspondió a una situación en la cual tanto el ganado como la población no eran numerosos. $Y$, sin embargo, ciertos grupos del campesinado indígena tuvieron un acceso muy restringido a la tierra, algunos no tenían tierras. Esta situación representó un problema grave para los burócratas reformistas Borbones en las últimas décadas del régimen colonial.

Este trabajo tiene dos objetivos ${ }^{1}$. En primer lugar, se sugerirá cómo se puede considerar esta paradójica

1 Este artículo ha sido presentado en la Conferencia de FLACSO sobre la Comunidad Andina durante el Siglo XIX, Quito, marzo 27- 
constelación de abundante tierra y baja densidad de la población, junto a una escasez de tierra para muchos campesinos. En la parte principal del trabajo se esbozará cómo, en un proceso vacilante y contradictorio, se disolvió esta paradoja entre la década de 1780 y fines de la década de 1820. El argumento que se presentará es un intento de atar cabos de cuatro variables centrales: las políticas de los Borbones $y$ de los primeros gobiemos independientes concernientes a la tierra y a la comunidad indígena; el desarrollo poblacional en el Altiplano; las distintas coyunturas comerciales y la manera cómo las élites provinciales respondieron a ellas; $y$, finalmente, las respuestas del campesinado a los continuos cambios sociales, económicos y políticos.

Se espera demostrar que durante las décadas que siguieron a la rebelión de Túpac Amaru, la política de la Corona con respecto a la tierra se tornó ambigua. Buscó, por un lado, detener futuras transferencias de tierras de las comunidades a las haciendas, pero, por otro lado, no llegó a mostrarse dispuesta a sancionar ni confirmar la precaria posesión de parcelas de tierra ocupadas desde aquella rebelión por un número cada vez mayor de campesinos, en especial forasteros. La política agraria se paralizó, dividida entre el miedo de provocar nuevas rebeliones y el deseo de apaciguar a la élite colonial $y$ mantener lo que quedara del "contrato colonial" entre la Corona y las comunidades indígenas. Cuando los seguidores de Bolivar tomaron el poder en 1824, en un inicio se sintieron libres de estas restricciones y esperaron llevar a cabo una arrasadora reforma agraria liberal que simultáneamente incrementara los ingresos del Estado, distribuyera la propiedad de la tierra entre una numerosa

30,1989, y en el Coloquio sobre Historia Latinoamericana, Latein-Amerika Institut, Freie Universitat Berlin, en junio de 1989. Agradezco los comentarios críticos de los participantes en ambos eventos. La traducción del original en inglés ha estado a cargo de Viviana Caro. 
población de pequeños propietarios y asegurara la libre circulación de la propiedad. Si bien se tuvo que reducir el alcance de algunos de estos objetivos, las medidas agrarias de 1828 convirtieron la situación de posesión precaria de miles de campesinos pobres en una de amplios derechos de propiedad. Así la combinación de la acción del Estado y de la presión de los campesinos llevó a una peculiar reforma agraria, incorporando elementos liberales y aspectos de la política de los Borbones, que estabilizó y ciertamente amplió temporalmente la base de propiedad de la tierra del campesinado de las comunidades.

Este trabajo se organiza en dos partes cronológicas. La primera abarca el final del periodo colonial. Empieza con un breve esbozo de la política y el pensamiento de la Ilustración española con respecto a la tierra y un perfil de los principales desarrollos que en las décadas anteriores a 1780 estaban dando lugar a la paradoja mencionada. A continuación sigue una discusión sobre la recuperación de tierras pertenecientes a la comunidad desde tiempos ancestrales por parte de los campesinos a partir de la rebelión de Túpac Amaru y del frágil y altamente volátil régimen de tenencia de la tierra durante las restantes décadas de la colonia. La segunda parte consistirá en una presentación detallada de la legislación sobre la tierra vigente a principios de la República y su efecto en el Altiplano.

\section{I}

Como suele suceder con cambios en las politicas económicas, las políticas agrarias de los Borbones reflejaron y respondieron tanto a un cambio en el clima de las ideas como a crecientes cuellos de botella y tensiones en el sector agrícola de la península. Hacia la década de 1750 España enfrentaba crecientes déficits en el abastecimiento de los principales granos, lo cual condujo 
a exorbitantes incrementos en los precios. Aún más serio para los observadores de la época, era que los pequeños arrendatarios confrontaban incrementos en las tarifas de arrendamiento mucho más agudos que los aumentos en los precios de los bienes agrícolas, amenazando la existencia de muchos de estos arrendatarios. A menudo se culpó a los latifundios por ambos problemas, a los mayorazgos de la antigua y la nueva nobleza y a las tierras que la Iglesia y otras instituciones corporativas poseian. Esta crítica tácita a los poderosos grupos señoriales $\mathrm{y} / \mathrm{o}$ corporativos que dominaban el régimen de tenencia de la tierra de España fue secundada y legitimida por conceptos fisiócratas, proto-liberales y regalistas de la economía política. El más famoso proponente de tales ideas reformistas fue, por supuesto, Gaspar Melchor de Jovellanos. En su "Informe sobre la ley agraria" de 1794 sugirió que la agricultura sólo prosperaría si la propiedad de la tierra podría circular libremente $y$ si no se acumulaba en las manos de unos pocos rentistas privados o corporativos. Sólo si un gran número de industriosos individuos podía adquirir fácilmente la tierra a precios razonables, los fondos se invertirian en la mejora de la agricultura y la producción aumentaría. Un desarrollo de este tipo era bloqueado en España en tanto que la mayor parte de la tierra se mantuviera fuera de circulación mediante los mayorazgos y los terrenos baldios $y$ propios de las municipalidades $y$ otras corporaciones. La idea central de Jovellanos para cambiar el régimen agrario del reino se encuentra en su exhortación, "Cortemos, pues, de una vez los lazos que tan vergonzozamente encadenan nuestra agricultura", un llamado para deshacer las vinculaciones de la propiedad de la tierra (Jovellanos, 1976:239; Sarrailh, 1957:565-68; Herr, 1989:47-77).

Tales ideas ya eran generalmente aceptadas entre los pensadorees ilustrados y los burócaratas durante la década de 1760, cuando el Concejo de Castilla de Carlos III comenzó a solicitar informes sobre las condiciones 
agrarias y propuestas de reformas a los intendentes provinciales $^{2}$. Pero estas ideas contenían una tensión interna de tal magnitud, que si bien fue largamente controlada durante el reinado de Carlos III, comenzó a brotar durante la década de 1790 y habría de dividir a la sociedad rural española por los próximos 150 años: nos referimos al conflicto entre la visión liberal de la libre, irrestricta circulación de la propiedad de la tierra para así orientarla al productor más eficiente, aún cuando esto llevara a una nueva concentración, y las contracorrientes igualitarias y comunitarias que enfatizaban la necesidad de una distribución más amplia y el mantenimiento de la solidaridad y la cooperación entre los productores. Mientras que la visión liberal se tornó claramente dominante en el pensamiento reformista español hacia fines del siglo 18 , las contracorrientes igualitarias también se expresaron con vigor. Por ejemplo, en 1764, el corregidor de Cáceres propuso una serie de medidas que permitieran que los pobres se beneficiaran de los pastos públicos y los baldíos, "con igualdad, méthodo, gobierno y utilidad", una política dirigida contra los abusos y la rapacidad de los caciques $y$ los administradores locales. El Intendente de Soria sugirió que aquellas grandes propiedades de tierra que fueran insuficientemente cultivadas pudieran ser explotadas por los habitantes pobres de la localidad (Sarrailh, 1957:570).

Dada la escala de los problemas en la estructura agraria de España y el alcance de las ideas reformistas, el resultado de las políticas reformistas fue ciertamente pobre. En vista de que la aristocracia y la Iglesia eran poderosos pilares de la monarquía, para los reformistas

2 Iwasaki (1987:133-62) ha sugerido que el informe de Jovellanos se basa en gran parte en el reporte de 1767 del Intendente de Sevilla, el peruano Pablo de Olavide, al Consejo de Castilla; sobre los reportes de fines de la década de 1760 ver especialmente Leonhard (1909:176230). 
era políticamente difícil enfrentar al latifundismo - a menudo los reformistas eran miembros de la nobleza baja (Jovellanos) o alta (Aranda). Por ello, concentraron sus esfuerzos en las vinculaciones, buscando especialmente una utilización más eficiente y justa de los terrenos municipales y una mayor libertad del yugo de los mayorazgos. Ya hacia 1712 se tomaron medidas para permitir el uso de las dehesas como tierra de cultivo, pero fue a partir del reinado de Carlos III que Madrid intervino más masivamente en el uso de los terrenos baldíos y las dehesas y propios de los pueblos. Durante la década de 1760 y comienzos de la década de 1770 en varios decretos se ordenaba la parcelación de estas tierras, permitiendo su uso para cultivar trigo (reduciendo asi los privilegios de la mesta), y se puso un límite a las tarifas de arriendo que las instituciones de la Iglesia, las municipalidades $y$ otras corporaciones podrian cobrar a sus arrendatarios (Herr, 1958:112-3; Leonhard, 1909:189-97 y 230-40) ${ }^{3}$.

A pesar de las esfuerzos de muchos burócratas reformistas en Madrid $\mathrm{O}$ en las capitales provinciales, la aplicación de estas medidas parece haber beneficiado mayormente a las élites locales. Como comentaba un observador contemporáneo, en las parcelaciones "se daba preferencia a los miembros de la administración y la gente rica y poderosa de la villa. Luego que estos habían escogido lo mejor, dejaban la tierra mala $e$ infértil a los campesinos, una injusticia que dio como resultado que las personas necesitadas se arruinaran y que aquellos que se encontraban en una buena situación aumentaran su capital y sus posesiones de tierra agrícola" (Franco, 1812. Citado en Leonhard, 1909:235). Los campesinos más pobres

3 Las nociones comunitarias sobre la propiedad se mantuvieron de manera muy fuerte en España durante los siglos XVI y XVII, un hecho que a menudo no se toma en cuenta y que también es de considerable importancia para la evolución de los regimenes de propiedad en América Española (Vassberg, 1984: caps. 1 y 3). 
también sufrieron con las parcelaciones al perder las tierras de pastoreo.

La Corona fué más cauta y procedió más lentamente en el caso de los mayorazgos, ya que los grupos involucrados eran infinitamente más fuertes que aquellos afectados por las medidas tomadas con las tierras públicas. Aún un reformista convencido como Pablo de Olavide, quien compartía la opinión de Jovellanos sobre las deletéreas consecuencias de los mayorazgos, concluyó que su abolición inmediata no era "ni prudente ni práctica" (Leonhard, 1909:220). Sólo unos meses antes de su muerte en 1789 Carlos III, finalmente, emitió el primer decreto que concernía a los mayorazgos. Este decreto simplemente exigía el permiso personal del Rey para fundar nuevos mayorazgos y permitía, en casos estrictamente limitados, que propiedades dejadas en mayorazgos se dividieran entre los herederos. Pero fue el rápido deterioro de las finanzas estatales durante la década de 1790 lo que exigió medidas más contundentes. En 1795 se impuso el pago de un derecho a la fundación de nuevos mayorazgos. Dos medidas posteriores adoptadas durante los siguientes cuatro años enlazaron el derecho de vender propiedades recibidas en herencia al establecimiento de un préstamo al Estado y otorgaron exempciones de impuestos y premios a todos aquellos que participaran en este esquema. Con estas medidas aquellos aristócratas empobrecidos o sobreendeudados vendieron cantidades apreciables de tierras de mayorazgos.

Pero estas medidas liberales de la reforma agraria tuvieron éxito sólo debido a que el estado, con el objetivo de recoger crédito de corto plazo, desembolsó considerables sumas de dinero como pago de intereses, premios y exempciones de impuestos a aquellos que vendian tierras de mayorazgos (Leonhard:1909:242-4). Por lo tanto, aun- 
que, como Richard Herr ha enfatizado, los reformistas pretendieron estar "del lado del pequeño agricultor y del arrendatario en contra de aquellos que explotaban la tierra sin trabajarla", la reforma que efectivamente se llevó a cabo mayormente benefició a los aristócratas empobrecidos que necesitaban dinero, al igual que a los nuevos estratos de caciques locales y a los emergentes grandes terratenientes burgueses (Herr, 1958:113; Sarrailh, 1957:570).

Sin embargo, mientras los preceptos liberales sobre la propiedad de la tierra triunfaban, la visión más equilibrada de Carlos III se plasma en un proyecto que tuvo éxito durante un breve período de tiempo: la colonia agraria que la Corona estableció con colonos alemanes en Sierra Morena en 1767. Los estatutos de la colonia llevan el sello tanto de Pedro Rodríguez de Campomanes, quien los escribió, como de Pablo de Olavide, el jurista ilustrado limeño que fue nombrado como primer superintendente para este experimento práctico del reformismo ilustrado. Cada colono recibiría una pequeña parcela de tierra de un tamaño proporcional al tamaño de su familia. Pero existirían terrenos comunes para el pastoreo al igual que algunas tierras de cultivo que se trabajarian de manera conjunta ciertos días. Los molinos y los homos y todas aquellas facilidades para el procesamiento pertenecian a la comunidad. Los edificios municipales, iglesias, escuelas se construirían mediante el trabajo cooperativo de todos los miembros de la comunidad. Los estatutos también sugerían a la misma comunidad tomar medidas para evitar la acumulación de la propiedad en manos de unos pocos (Sarrailh, 1957:569).

Los estatutos demuestran que la estructura agraria ideal de los reformistas borbones se fundamentaría en la propiedad privada y el mantenimiento de la cooperación entre los productores. Para salvaguardar la distribución en el largo plazo de 
parcelas de tierra relativamentte iguales entre los labradores industriosos la Corona consideró como necesidad permanente la supervisión pública del mercado de tierras. De hecho, la principal diferencia entre las nociones puramente liberales sobre la propiedad de la tierra $y$ aquellas de los burócratas ilustrados de fines del siglo XVIII se encontraba en el mayor rol concedido por éstos últimos al estado para la creación y el mantenimiento de la estructura agraria "ideal". La Corona necesitaba intervenir en las relaciones agrarias para retirar los obstáculos a la generación de riqueza agrícola. Y en la definición de los objetivos fundamentales de tales reformas el bienestar del "sujeto" individual no fue separado conceptualmente del engrandecimiento de la nación, personificada por la Corona. El estado fuerte, que todavía no estaba plenamente diferenciado de la sociedad civil, iba a constituírse tanto en el fin de las reformas agrarias como en su instrumento. La visión ideal de los reformadores de las relaciones de propiedad agraria puede expresarse como una triada de elementos: Una propiedad liberada de vínculos corporativos, una amplia distribución de la propiedad entre los agricultores cooperativos, y, a manera de pieza clave de esta visión, una Corona que engloba los intereses del reino manteniendo el equilibrio entre estos principios potencialmente en conflicto. Esta visión encuentra perfecta expresión en las palabras del corregidor de Cáceres, anteriormente citado: "igualdad, méthodo, gobiemo y utilidad".

¿Aquellas nociones borbónicas ilustradas sobre la propiedad agraria influenciaron los patrones de tenencia de la tierra en un lugar tan lejano como el Altiplano peruano? $Y$, si lo hicieron, de qué manera? Para responder 
enumeraré los principales factores que dieron forma a la evolución de este patrón durante el siglo que precedió a la rebelión de Túpac Amaru, antes de discutir sus dimensiones en la irrupción de la crisis alrededor de 1780 .

1. Para comprender el impacto de la política de la Corona al igual que la coyuntura económica en las comunidades, es crucial considerar su desarrollo demográfico. La población indígena en el Altiplano Norte parece haber alcanzado su nadir durante la epidemia de 1718-20. Las retazas de tributo sugieren que la población creció bastante rápidamente durante las décadas de mediados del siglo (Jacobsen, 1982:32-3).

2. En el Norte del Altiplano la expansión de las haciendas continuó vigorosamente durante los primeros tres cuartos del siglo XVIII, proceso que estuvo acompañado de un período de auge del complejo de obrajes del Cusco para el cual el Collao era la principal fuente de materia prima (Salas, 1986:202-32; Moscoso, 1965). Sacerdotes de las parroquias, kurakas y los empresarios españoles "incorporaron" tierras en las cuales anteriormente las comunidades indígenas les habían permitido mantener sus rebaños en el marco de las relaciones recíprocas y/ - como parte de las funciones de las autoridades tradicionales. Impedida por la insuficiente y no confiable mano de obra y la creciente pérdida de ganado en los pastos comunales no incorporados, debido al robo y la mezcla de rebaños, la élite provincial estaba, en efecto, intentando establecer un régimen de propiedad privada en los pastos comunales cuyo usufructo les había sido otorgado anteriormente por las comunidades. Esto no era tanto una expansión de las haciendas en las tierras comunales, sino más bien un cambio fundamental del significado social de la tierra, la conversión hacia una noción de la tierra que implicaba la apropiación privada y la dominación. Un uso de la tierra con esas características había existido en algunas áreas limitadas del altiplano antes del siglo XVIII. 
Pero ahora se expandía hacia áreas en las cuales las comunidades no habían sido afectadas. Durante el siglo que precedió a la rebelión de Túpac Amaru el número de haciendas en una provincia del Altiplano, Azángaro, creció de 48 en 1689 a 110 en 1825-304.

3. Durante el siglo XVIII la política protectora de la administración colonial hacia los indígenas se tornó conflictiva $y$ puede muy bien haber contribuído a la disminución de la propiedad comunal de la tierra. Por un lado, la Corona se preocupó cada vez más por que las comunidades tuvieran la suficiente tierra para que las familias pudieran subsistir y cumplir sus obligaciones fiscales y de trabajo. Entre 1710 y 1780 las composiciones de tierra en favor de las comunidades se hicieron más frecuentes, mejorando el título mediante el cual las comunidades poseían sus tierras (Piel, 1975:I:191ff; Spalding, 1984:183). Pero, simultáneamente, se tendió a dar menos validez a los reclamos sobre tierras de "tiempo inmemorial". Más bien, los burócratas ilustrados y los juristas querían fundamentar el derecho de posesión de la tierra de los miembros de la comunidad en el principio de que "las tierras asignadas a los pobladores fuesen todas iguales $\mathrm{y}$ acomodadas a lo que una familia puede necesitar y beneficiar", como Joaquín Costa parafraseó las ideas de Campomanes (Costa, (1898),1983:VII:174). A mediados del siglo XVIII tales preceptos calaron gradualmente en la práctica jurídica. Los representantes de la Corona comenzaron a llevar a cabo periódicas redistribuciones de tierra en las comunidades. Cada familia con derechos comunitarios plenamente reconocidos recibiría una cantidad uniforme de tierra, que variaba de región en región. La "demasía" de tierras de la comunidad se vendería en subastas, creando una fuente más de ingresos

4 La evidencia que sustenta mi suposición de que la mayor parte de estas nuevas haciendas se formaron antes de 1780 se presenta a continuación. 
NILS JACOBSEN

para el tesoro del rey español (Spalding, 1973; 1975:II: 1:118; 1984:205-8).

Una instrucción real del 15 de octubre de 1754 facilitó el proceso de expansión de la hacienda, al simplificar el proceso burocrático de venta y composición de las tierras de la Corona en las colonias de América. Buscaba incluír en la producción a "muchos sitios $y$ tierras" que la Corona aducía no estaban siendo cultivados debido a títulos inciertos. Al mismo tiempo que protegía de manera expresa las tierras de la comunidad indigena (título 2), exhortaba a los jueces de tierras a no usar "rigor con las (tierras comunales) que ya poseyeran los españoles y gentes de otras castas". Las tierras que se encontraban en posesión de los españoles desde antes de 1700, aun cuando no tuvieran título, no podrían ser gravadas con nuevas tarifas de composición por los jueces visitadores, debido a su "antigua posesión", si es que en ese momento estaban siendo cultivadas (título 4$)^{5}$. Sobre la base de esta cédula una gran extensión de tierra se vendió o fue confirmada mediante la composición entre 1754 y $1780^{6}$.

4. Entre 1720 y 1780, un período de vigoroso crecimiento de la población siguiendo al nadir de la población indigena del Altiplano, esta política -combinada

5 "Compilación de Reales Cédulas, Provisiones, Leyes, Instrucciones y Procedimientos sobre repartimientos y composición de tierras en favor de los Indios, desde el año de 1591 hasta 1754; incluyendo además los Decretos y Disposiciones que fueron dictados por el Libertador D. Simón Bolivar, en los años de 1824 a 1828, inclusive... (cont.), Revista del Archivo Nacional del Perú:XX:2438-46 (1956); Roel (1970:276-7).

6 José F. de Abascal y Sousa, Memoria de Gobierno (1816), eds. Vicente Rodríguez Casado y José A. Calderón Quijano, 2 vols. (Sevilla, 1944). Ver vol. I:286. Para el devastador efecto de las politicas de los Borbones sobre las tierras de las comunidades indigenas en Nueva Granada, ver Gonzales Luna, 1977:III:201-19. 
con las exaltadas presiones de las élites provincialesprodujo severos problemas en las comunidades del Altiplano. En varias comunidades no habia suficiente tierra agricola ni pastos para la subsistencia de la familia y el cumplimiento de sus obligaciones para con las diferentes autoridades civiles y religiosas (Spalding, 1984:205-8). Ya en la década de 1740 Jorge Juan y Antonio de Ulloa notaron que "...ya al presente son muy reducidos los ámbitos que les han quedado [a los Indios] y la mayor parte de ellos están sin ningunas [tierras]" (Juan y Ulloa, s.f.:1:318-9).

Los conflictos con respecto a la tierra, tanto entre las comunidades como entre las comunidades $y$ las haciendas, se hicieron muy frecuentes en el Altiplano durante las décadas de mediados del siglo XVIII. Los forasteros, descendientes de campesinos que no habian nacido en la comunidad en la cual vivian, encontraron cada vez más difícil el arrendar tierras de las comunidades o de las familias más pudientes de originarios, en tanto que la reducida base de tierra disponible era apenas suficiente para dotar a las familias de originarios con los suficientes topos de tierra. Los jueces tendieron a favorecer a los originarios en los conflictos sobre la tierra, aun cuando a veces las parcelas vacantes fueron asignadas a los forasteros y a otros campesinos sin tierra (Spalding, 1975:117) ${ }^{7}$. En las luchas de las comunidades con los hacendados españoles o los kurakas sobre los derechos a tierras especificas, la administración local y los tribunales a

7 Litigio sobre la invasión de la Estancia Hallapise, set. 5, 1761. Archivo Nacional de Bolivia (ANB), Materiales sobre tierras e indios, 1761, no. 102; para un caso en el cual un cacique asignó una parcela vacante de tierra a un forastero, ver "Documento para la historia de Azángaro", Makaya, no. 2 (Azángaro:junio 1971), s.p.; para el impacto del crecimiento de la población de forasteros sobre las estructuras comunales, ver Wightman (1990:cap. 4). 
menudo fallaban en contra de las comunidades entre la década de 1750 y $1780^{8}$.

5. Contrariamente a las intenciones de las medidas reformistas, la igualdad de la distribución de la tierra al interior de la comunidad no se incrementó a mediados del siglo XVIII. Muy por el contrario. En tanto que las frecuentes redistribuciones de parcelas al interior del cada vez más reducido dominio legal de las comunidades hizo más difícil la expansión de las propiedades, las familias campesinas relativamente pudientes deben haber llegado a poseer considerables extensiones de tierra en dominio absoluto fuera de los límites de las comunidades, sin abandonar sus privilegios al interior de éstas ${ }^{9}$. Los

${ }^{8}$ Ver, por ejemplo, los procedimientos llevados a cabo por los ayllus Nequeñeque, Picotani, y Chuquini (anexo Munañi de la parroquia de Azángaro) contra su kuraka Diego Choquehuanca sobre la apropiación de tierras, reclutamientos involuntarios de mano de obra y otros abusos ante la Audiencia de Charcas, 1760-2; ANB, Materiales sobre Indios y Tierras, EC Año 1762 no. 144.

9 Ver, por ejemplo, el caso de Mateo Turpo, quien había recibido el título de una tierra en el ayllu de Sillota, parroquia de Asillo, por composición ante el Protector de Indios en Potosí, Francisco Mina, en fecha no especificada durante el periodo colonial. Registro de la Propiedad Inmueble, Puno, tomo II, folio 240, Partida CV Asiento no. 1 , dic 15, 1900; Poole concluye para la provincia ganadera de Chumbivilcas que muchos "indios ricos" se habian apropiado de tierras comunales en el curso del siglo XVIII (1987:268-9). Spalding fue la primera en enfatizar la creciente diferenciación social al interior de las comunidades desde el siglo XVII y la nueva calidad de esta diferenciación social basada en el acceso diferenciado a la tierra dentro de un esquema que cada vez tenía menos elementos de las nociones andinas de reciprocidad y más elementos de la acumulación privada. Ella también enfatizó el significativo cambio en la política con respecto a la tenencia de la tierra indígena que la administración colonial llevó a cabo a partir de las décadas de mitad del siglo XVIII, que buscaban crear una mayor igualdad en la tenencia de la tierra y el retiro de "tierras sobrantes" en las comunidades. Ella conectó correctamente este cambio con el intento de los administradores borbones de poner nuevamente en vigor la extracción forzada de mano de obra de las comunidades para el beneficio de los mineros, los dueños de haciendas y los obrajeros, subestimando 
campesinos que adquirian tierras en dominio absoluto a menudo provenían del rango de los principales, las familias más notables en las comunidades, que monopolizaban los más altos cargos. Por otro lado, la acumulación de tierras y rebaños que estas realizaban a veces era parte de una estrategia para desafiar al kuraka por su cargo ${ }^{10}$. Precisamente, al igual que en España con la parcelación de los propios $y$ los éjidos municipales, en la parte sur de la Sierra las periódicas redistribuciones de la tierra de las comunidades llevaron a fraudulentas apropiaciones por parte de los kurakas y otras aurtoridades locales ${ }^{11}$.

6. Sin embargo, a pesar de que los conflictos sobre las tierras eran cada vez más intensos al interior de las comunidades $y$ entre los campesinos y las haciendas en expansión, los reclamos de escasez de tierra en el Altiplano de fines del siglo XVIII continúan siendo

las nociones ilustradas de los Borbones de crear agricultores mas productivos. Pero, donde creo que su análisis no es correcto es en su suposición de que esta nueva política logró precisamente lo que se proponia hacer, esto es, crear un nivel mas uniforme de acceso a la tierra para todos los campesinos de la comunidad, de manera tal que los obligaria a recurrir crecientemente al trabajo fuera de la comunidad para poder lograr la reproducción de sus familias. Este objetivo podía ser logrado mas eficazmente con el incremento de presiones fiscales (entre otras), ratificadas por la Corona durante la segunda mitad del siglo XVIII. Estas crearon la necesidad de recurrir a fuentes de ingreso no agrícolas inclusive para familias relativamente pudientes. Para un suscinto resumen del punto de vista de Spalding, ver (Spalding, 1975).

10 Comunicación personal de David Cahill, febrero de 1989; la identificación de los mas grandes propietarios de tierras campesinas como principales se basa en información para la provincia de Azángaro de mediados del siglo XIX.

11 Alonso Carrio de la Vandera (1966 (1782):76) culpó exclusivamente al "fraude de los caciques, alcaldes y demás mandones que agregaron a sus tierras los topos que el rey concedió a los naturales para su subsistencia y la de su familia" por la total carencia de tierras de numerosos indigenas campesinos. El vió en estos abusos la razón para lo que él percibió como una disminución de la población indígena. 
enigmáticos desde la perspectiva actual. Después de todo, como se mencionó al inicio, la densidad de la población era bastante baja y la tierra continuaba teniendo poco valor. Aún más, a pesar de la incorporación de nuevas haciendas durante los primeros tres cuartos del siglo XVIII, su número $y$ extensión total eran modestos comparados con la situación de principios del siglo XX. Ciertamente, estimados conservadores sugerirían que en la década de 1820 el campesinado todavía controlaba por lo menos el $50 \%$ de la tierra cultivable y de pastoreo en la provincia de Azángaro (Jacobsen, 1982:apéndice 2:834-41).

Por lo tanto, para resolver el enigma tenemos que considerar los efectos del creciente nivel de explotación al cual la mayoría de los grupos campesinos estuvieron sometidos en el transcurso del siglo XVIII. Los pagos $y$ servicios que los indígenas debían a los representantes de la Corona y la Iglesia, al igual que a otros miembros de la élite provincial, los obligaban a vender o beneficiar un número cada vez mayor de sus animales ${ }^{12}$. Ya durante la década de 1770 el uso del ganado, por los campesinos ganaderos, para pagar el tributo, las deudas de los repartos del corregidor y otras exacciones, impidieron el crecimiento natural de los rebaños $e$ incluso podría haberlos disminuído $^{13}$. Los funcionarios de la Corona, no muy atentos

12 También en varias partes de Europa existieron segmentos sustanciales del campesinado que para fines del siglo XVIII, tenian suficientes recursos de tierras, pero que al enfrentar crecientes rentas, impuestos $y$ derechos de arrendamiento, apenas podian guardar una parte de sus productos para la reproducción simple de sus familias. Esta fue por supuesto una de las bases para el surgimiento de ideas de la reforma agraria de los Borbones en España, como se ha señalado anteriormente. Para las "regiones serviles" de Europa en general, ver Blum (1978:caps. 9 y 10); para una región específica en Prusia, ver Harnisch (1968:219, 21).

13 Carrio de la Vandera (1966 (1782):63) sugiere que los criadores de cameros en el Collao, "debido a su pobreza", vendieron 
a las causas de la pobreza indígena relacionadas al sistema socioeconómico al cual ellos representaban, atribuyeron la merma de los rebaños a la "infertilidad" del suelo del Altiplano y simplemente supusieron que los pastos no podian mantener más animales $^{14}$. A partir de aquí sólo era necesario un paso más para concluír que el acceso de los campesinos a la tierra se había tornado peligrosamente insuficiente.

En las décadas previas a la rebelión de Túpac Amaru, la élite provincial de Azángaro (corregidores, sacerdotes, kurakas y hacendados "hispanizados"), había incrementado la extracción de excedentes de la economía campesina en el momento en que la administración virreinal imponía nuevos impuestos a los indígenas. Este "ajuste" condujo a lo que puede ser calificado como "sobreexplotación", con serias consecuencias para el conjunto de la sociedad. La colusión entre los diferentes sectores de la élite se estaba desbaratando en la contienda de corregidores, sacerdotes, kurakas y hacendados por el limitado ingreso derivado de la mano de obra, la tierra y la producción indígenas ${ }^{15}$. No menos serio era el hecho de que la excesiva extracción de excedente llevó a muchos campe-

carneros para que fueran beneficiados "cada año, o cuando más cada año y medio", si ésto se hubiera practicado con las ovejas madres, se habria limitado seriamente la reproducción del rebaño.

${ }^{14}$ Esta visión fue expresada por el Protector de Indios de la Audiencia de Lima, Dr. José Baquijano y Carrillo, en su resumen sobre una petición para reducir las tasas del tributo que los indígenas tenían en el partido de Paucarcolla. El 9 de setiembre de 1779, la Audiencia de Charcas se pronunció a favor de su petición. Ver ANB, Materiales sobre Tierras e Indios, EC Año 1779, no. 224.

15 Para evidenciar el creciente conflicto intra-élite, ver Manuel de Amat y Juniet, Memoria de Gobierno, eds. Vicente Rodríguez Casado y Florentino Pérez Embid (1947:200); Cahill (1982:241-76); O'Phelan (1986:340-56); Hinojosa (s.f.:232-3). 
sinos pobres a abandonar sus comunidades, temporalmente o de manera definitiva, buscando refugio en las ciudades, la montaña o en otras comunidades, donde, al menos por un tiempo, podrían evitar el pago de elevados derechos. De esta manera, la creciente extracción de excedentes contribuyó al surgimiento de campesinos sin tierras.

Estos, entonces, fueron los elementos que, para fines de la década de 1770 y en la parte norte del Altiplano, estaban en la base de la paradójica costelación de bajos niveles de valor de la tierra, baja densidad de la población y creciente escasez de tierra para muchos campesinos de las comunidades. El vivo interés al interior de la élite provincial -desde kurakas y funcionarios de la Corona hasta sacerdotes y españoles- por incorporar las tierras comunales a las haciendas, coincidió con el incremento de la población en las comunidades para intensificar los conflictos sobre la tierra. A pesar de sus máximas distributivas, las políticas borbónicas con respecto a la tierra, en plena vigencia entre principios de la década de 1750 y 1780 , tendieron a exacerbar las dificultades de los forasteros $y$ los originarios empobrecidos para encontrar suficiente tierra para la reproducción familiar al interior de las comunidades. Los jueces de tierra y los administradores de los Borbones estaban despojando a éstos de toda "tierra en demasía". La política de facilitar la venta y composición de tierras realengas (incluyendo las tierras sobrantes de la comunidad) también disminuyó la opción de los campesinos pobres de obtener posesiones de tierra fuera de las comunidades. Ellos carecían tanto de dinero como de influencia para beneficiarse de los dispositivos de la Corona. La abultada extracción de excedentes por todos los sectores de la élite provincial, al igual que por la Hacienda Real, hacia la década de 1770 hi- 
zo que la reproducción de la familia campesina basada en la agricultura y otras actividades tradicionales se hiciera más incierta, inclusive para aquel estrato de campesinos que contaba con posesión de tierras mejor aseguradas. Por tanto, entre 1720 y 1780, las crecientes presiones de las élites provinciales $y$ de la Hacienda Real llevaron a un deterioro del acceso de los campesinos a la tierra y de la seguridad de su posesión. Un proceso comparable a lo sucedido en varias partes de Europa.

\section{III}

La insurrección a lo largo de una gran parte del sur de los Andes iniciada en Tinta por el kuraka José Gabriel Condorcanqui, venerado por sus seguidores como Túpac Amaru II, ayudó a que se dieran cambios tanto en la política de la Corona como en las constelaciones regionales de poder. Estos cambios tenían incidencia en los patrones de tenencia de la tierra, especialmente en el norte del Altiplano, donde el movimiento alcanzó su mayor intensidad y duración. Este no es el lugar para discutir las causas de la insurrección, su compleja base social y su proyección ideológica ${ }^{16}$. Lo que interesa en este trabajo es subrayar el duradero efecto que ésta, en conjunción con cambios económicos y administrativos más amplios, ejerció en la economía política de la sierra sur peruana. Las muertes, la destrucción de las haciendas, la pérdida de cosechas y ganado, la quema y el saqueo de obrajes, los enconados sitios de Cusco y La Paz y el evidente costo para contener la insurrección, obligaron a

16 La bibliografía sobre la "Gran Rebelión" es vasta. Ver especialmente O'Phelan (1985); Lewin (1957); y varios ensayos en Stern (1987). Para la parte norte del altiplano ver el minucioso trabajo de Ramos Zambrano (1982). 
la Corona y a las élites provinciales a recalibrar sus politicas y relaciones para con la comunidad campesina indígena, la base popular del movimiento. A la vez que los rebeldes sufrieron la derrota militar, el alto precio que aquellos exigieron de los triunfadores significó para la administración virreinal las posibilidades de un nuevo ciclo de rebeliones. La vía elegida se expresó en una fuerte dosis de represión y el incremento del control estatal (reforzamiento de las milicias, las intendencias, creación de la Audiencia del Cusco) y en el establecimiento de barreras más estrictas a la explotación del campesinado por varios sectores de las élites provinciales. Ahora, para la Corona era crucial que el "contrato colonial" con el campesinado indigena, considerablemente dañado durante las cinco décadas anteriores, no se derrumbara.

Así, la rebelión de Túpac Amaru introdujo una serie de cambios en el Altiplano. La posición de los kurakas fue debilitada, a través de una serie de medidas tomadas por la administración virreinal. No tanto para controlar los abusos de la nobleza indígena contra sus súbditos, sino más bien para evitar que estos miembros privilegiados de la sociedad colonial volvieran a liderar un levantamiento. Los cacicazgos ya no serian hereditarios. En su lugar, funcionarios de la Corona señalarian "hombres de buen carácter", conocidos por su lealtad al rey de España. Inclusive podrian ser españoles. En muchos casos los kurakas tuvieron que entregar el gobierno de las comunidades, incluyendo la recolección de los tributos, a los alcaldes (Fisher, 1966:223; Sahuarara, 1944:372-6) ${ }^{17}$.

17 Para las dificultades de los poderosos clanes de Choquehuanca y Mango Turpo, kurakas de la provincia de Azángaro, ver ANB, Materiales sobre Tierras e Indios, EC año 1782, no. 57 y EC año 1783 , no. 7; Carta del 3 de enero 1925 de Manuel Isidoro Choquehuanca a un periódico de Arequipa, reimpresa en Luna (1946:100-2, pie de pág. 2; ibid.:81-98; "Oficio del Señor Antonio Zernadas Bermudez (Oidor de la Audiencia de (uzco) al Señor Gobernador Intendente de Puno", 18 de Febrero 1791, en Cornejo (1956:216-7), y Salas (1957:29-30). 
La rebelión tuvo un impacto en la tenencia de la tierra que todavía no ha sido completamente reconocido por los estudiosos. Las tropas de Túpac Amaru y las bandas independientes de campesinos ocuparon muchas haciendas durante los quince meses de control ininterrumpido de la parte norte del Altiplano. En algunos casos, como por ejemplo durante el levantamiento en Oruro en febrero-marzo de 1781, los campesinos indigenas obligaron a los dueños de las haciendas a firmar contratos notariales que convertían a los campesinos en dueños legales de las tierras de esas haciendas. En Azángaro, los títulos de las estancias privadas y de la Iglesia fueron quemados (Lewin, 1957:576) ${ }^{18}$. Por supuesto, gran parte de la tierra ocupada por los campesinos indigenas durante la rebelión fue posteriormente recuperada por los antiguos dueños. Pero muchos residentes españoles de la región habían sido asesinados o habían abandonado definitivamente el Altiplano. Más de veinte "españoles" se fueron definitamente de una sola parroquia (Arapa) en la provincia de Azángaro durante o inmediatamente después de la rebelión $y$, en 1803, un reporte sobre la Intendencia de Puno todavía describía al Collao como "muy despoblado de gente española $y$ de otras castas desde el tiempo de la revelión de Tupamaro y los Cataris". Sólo ocho familias de origen peninsular o criollo ("su vecindario") residian en el pueblo de Azángaro en 1813 (Roel, 1970:223) ${ }^{19}$.

Parte de la tierra ocupada por los campesinos rebeldes nunca fue efectivamente recuperada por los grandes

18 Ver también Comité Arquidiocesano (1983:368). Existen algunos indicios de que Túpac Amaru y sus seguidores intentaron llevar a cabo extensas distribuciones de tierras de las haciendas entre las comunidades indigenas, ver Vega (1969:29-31).

19 Ver también "Expediente sobre la queja presentada por el pueblo de Azángaro para que el govierno virreynal ponga término a los desmanes que comete el subdelegado Escobedo", 2 de abril 1813, BNO, Ms D 656; "Breve reseña histórica del pueblo de Arapa", en Makaya (Azángaro), no. 5, marzo de 1976, p. 9. 
terratenientes españoles. No sólo las haciendas privadas fueron afectadas por la rebelión, sino también aquellas de los kurakas y de la Iglesia. En 1799, casi dos décadas después de la derrota de Túpac Amaru, los campesinos indigenas todavía ocupaban tierras en la parte norte del Altiplano, que antes de la rebelión habían sido reclamadas por las iglesias parroquiales y los conventos. Muchas haciendas de la Iglesia fueron reducidas a la mitad de su extensión inicial, según las quejas de los recolectores de derechos eclesiásticos en Azángaro y en las provincias vecinas. El capital en ganado de las haciendas se encontraba sufriendo "anualmente crecidas desolaciones" debido a la escasez de pastos, aún cuando los jueces reales habían ordenado repetidamente a los campesinos que restituyeran estas tierras a la Iglesia

"...no ha cido posible reducirlos a sus justos términos. Con esta tolerancia graza el mal con los días a tanto grado, que dentro de poco tiempo irán feneciendo dichas estancias, y por consiguiente cesarán también el Culto Divino y sufragios espirituales que se hacen en beneficio de los mismos indios" 20 .

Los campesinos utilizaron el caos de los meses de rebelión y el desorden en el cual cayó la Iglesia en la parte norte del Altiplano durante los siguientes años para deshacer lo ocurrido durante gran parte del siglo XVIII: la incorporación en haciendas ganaderas de las tierras comunales otorgadas informalmente para el uso de las parroquias y cofradías.

La cantidad de ventas y composiciones de tierras realengas, incluyendo las tierras otorgadas en usufructo a

20 Petición de los curas de la parroquia de Orurillo y Santiago de Pupuja al Obispo del Cusco, 5 de octubre 1799, en Comité Arquidiocesano (1986:368) 
las comunidades indígenas, disminuyó considerablemente luego de la rebelión de Túpac Amaru. La Ordenanza de Intendentes de 1782 todavía había dado a los intendentes el poder de investigar los títulos de tierra y corregir las apropiaciones abusivas de tierras comunales, pero también les permitía llevar a cabo nuevas ventas y composiciones. Sus decisiones podian ser apeladas en la Junta Superior de Real Hacienda en Lima. Los intendentes nombrarían jueces de tierras agrimensores en cada partido. Pero, dado el gran número de apropiaciones de facto de tierras durante el siglo XVIII, y las "frecuentes peticiones" $e$ "innumerables [casos]" que se encontraban pendientes de arreglo ante la Junta Superior por abusos de los jueces remensuradores, el 12 de agosto de 1788 el Virrey de La Croix suspendió la Real Instrucción del 15 de octubre de 1754, retirando legalmente las bases para cualquier futura composición. En la justificación de este decreto, él señalaba que los despojos de tierra fueron mayormente cometidos en contra de los indígenas, debido a que éstos no sabían como defenderse y carecían de recursos para hacer oír su voz. Debido a esta razón, "más que suficiente en sí misma para mi resolución [de detener futuras composiciones]", añadió

"también la consideración de las recientes revoluciones del Reyno y el deseo de mantenerlo en la paz y tranquilidad, cuyo establecimiento fue el primer objeto de mis atenciones desde que tomé posesión de este Gobierno" (Fuente (ed.), 1859:V:91-3).

Consecuentemente, entre fines de la década de 1780 y 1816 por lo menos, la administración virreinal expidió títulos legales de venta o composición de tierras de la Corona sólo en aquellos "casos muy raros" en los cuales el poseedor de tierras sin documentación informaba a los funcionarios acerca de estas posesiones, para "calmar 


\section{NILS JACOBSEN}

su conciencia u obtener un título legítimo" (Abascal en Fuente, 1858:1:286-7).

Sin embargo, durante la administración de José Gonzales y Montoya como Intendente de Puno entre 1801 y 1808 se llevaron a cabo nuevas ventas de tierras de las comunidades, algunas de ellas en Azángaro. En noviembre de 1802 Nicolás Montesinos, alcalde recaudador de tributos de Asillo, presentó al Intendente una petición en su favor para la composición y venta de la Estancia Caiconi. Montesinos aducía que esta estancia, ubicada a cerca de cuarenta kilómetros al noreste de Asillo, en las montañas de la Cordillera de Carabaya, constaba de tierras de baldío que pertenecían a la Corona. Había testigos que apoyaban su demanda. Estos explicaron que "por costumbre" la tierra había sido utilizada desde tiempo inmemorial por los "caciques y recaudadores de tributos" de Asillo. Cuando una nueva persona ocupaba ese cargo, asumía la posesión de Caiconi como una dependencia del cargo, sin ningún tipo de reclamos hereditarios por parte de los herederos de sus predecesores. Los testigos, todos residentes españoles de Asillo, se expresaron vagamente sobre los derechos que la comunidad indígena podría haber tenido sobre las tierras de la estancia. Uno de ellos simplemente declaró que "el común de Indios del Ayllu Hila donde se halla cituada la referida Estancia nunca la ha poseído". Pero de acuerdo a otro testigo "no han disfrutado los Indios de la comunidad llas tierras de Caiconi], aunque se dice pertenecen a ella...". Sin embargo, todos los testigos estuvieron de acuerdo en que un cambio en el "régimen de propiedad" de Caiconi no dañaría a los indigenas de la comunidad, dado que, en primer lugar, ellos nunca se habian beneficiado de ella $y$, más aún, ellos poseían sufi-cientes tierras de cultivo $y$ pastoreo. Por el contrario, ellos enfatizaron, que la composición y venta de Caiconi pondría fin a las pérdidas ocasionadas al Tesoro Real, ya que nunca se habian pagado los impuestos sobre estas tierras. Las autoridades 
reales de Azángaro y Puno, de acuerdo al caso, siguieron todos los pasos acostumbrados para conferir el título de Caiconi a Montesinos, incluyendo el ofrecimiento público de la tierra en la plaza de Asillo en nueve ocasiones diferentes por un pregonero. Luego que Montesinos hubo pagado el valor fijado al Tesoro Real en Chucuito durante el año de 1803, el asunto fue enviado a Lima para que la Junta Superior de Hacienda expidiera el título correspondiente. En Lima, sin embargo, el trámite fue detenido $y$, a pesar de que Montesinos se encontraba en posesión de Caiconi, hacia 1807 todavía no tenía el título 21 .

Un decreto de la Junta Superior del 19 de agosto de 1809 declaró nulas las ventas y composiciones expedidas bajo la administración del Intendente Gonzales en Puno. A pesar de que ellas habían sido aprobadas por los funcionarios provinciales bajo el pretexto de ser de interés para el Tesoro Real (claramente, una preocupación central de los administradores borbones), ahora iban en contra de un objetivo mas amplio, el de pacificar al campesino de las comunidades y asegurar sus tierras. Sin embargo, para abril de 1813 el Cabildo de Azángaro, el cual "se compone la mayor parte de los Indios leales que se han envejecido sirviendo al Soberano", reclamó formalmente que muchas de las tierras vendidas ilegalmente bajo los auspicios de Gonzales todavía no habian sido devueltas por sus nuevos dueños a los indígenas de la comunidad $^{22}$.

Estas pugnas sobre la tierra durante las décadas posteriores a la rebelión de Túpac Amaru evidencian los cambios que se estaban dando en la noción de propiedad $y$ el surgimiento de una nueva clase de conflictos entre

21 "Composición y venta de la Estancia Caiconi", 16 de noviembre de 1802. Archivo de la Prefectura, Puno.

22 "Expediente sobre la queja presentada por el pueblo de Azángaro....", 2 de Abril 1813 (ver nota 19). 
los sectores indigena y español. Las parroquias, los kurakas $e$ inclusive los residentes mestizos 0 criollos inicialmente habian recibido derechos de usufructo de las tierras de pastoreo de las comunidades indígenas para propósitos circunscritos y bien definidos: usar los productos de las ovejas, reses o camélidos que fueran ubicados en dichos pastos, para sostener un hospital, un fondo especial de la parroquia, o para el equipamiento de un santo patrón; a un kuraka se le otorgarian tierras como parte de su cargo ("tierras de oficio"), basado en el reconocimiento de los servicios recíprocos que se suponía él prestaba a la comunidad; criollos y mestizos podian construír capillas rurales o locales cuyo mantenimiento naturalmente provendría de las tierras comunales adyacentes (Sallnow, 1983:2:2:39-56). Para las comunidades, tradicionalmente, los derechos de uso de la tierra no se habían basado en nociones de propiedad universales, sino más bien en arreglos muy específicos que relacionaban el control material sobre la tierra con el mantenimiento de obligaciones mutuas entre la comunidad y la persona o institución que se beneficiaba del usufructo (Mayer, 1977:24-5:59-72). En el transcurso del siglo XVIII esta noción de uso de la tierra se vió cada vez más desafiada por las autoridades coloniales y las élites provinciales, un cambio que tuvo sus orígenes tanto en el intento de lograr un control más efectivo sobre la crianza de ganado como en la penetración de los conceptos ilustrados sobre la propiedad. Si el beneficiario de los derechos de uso tradicionales comenzaba a construir un caserío en las tierras y trataba a los pastores como yanaconas, con tasa de tributo específica, la comunidad consideraría esto como una ruptura de los derechos de uso acostumbrados e iniciaría acciones para restaurar el antiguo status: los campesinos llevarian ganado a los pastos que se encontraban en disputa y la comunidad asentaría peticiones $y$ litigios con las autoridades. Pero antes de 1780 parece que las comunidades en el Altiplano tuvieron poco éxito con medidas 
de este tipo. Las élites provinciales estaban relativamente unidas $y$ las autoridades todavía no se preocupaban por supuestas escaseces de tierra para los campesinos. En cambio, veían cada nueva composición en favor de un propietario como paso hacia un orden económico más racional. Pero para 1780 ésto había cambiado. Las luchas internas entre los corregidores (o sus sucesores), sacerdotes, kurakas y dueños de haciendas crearon oportunidades para que las comunidades recuperaran sus tierras (Cahill, 1982) ${ }^{23}$. Las comunidades también podian encontrar eco a sus demandas en la corte $y$ entre los magistrados de alto nivel. El miedo a las rebeliones campesinas por la falta de tierra había llevado a la reducción de las enajenaciones de tierras de la comunidad en favor de criollos y mestizos.

De igual importancia para el cambio de curso debe haber sido el hecho que el interés en expandir las haciendas ganaderas o incorporar nuevas decayó considerablemente luego de la década de 1780, debido a que la demanda por productos pecuarios permaneció estancada e inclusive cayó. Cerca a 1810, por ejemplo, el hacendado Gregorio Choquehuanca, hijo del fallecido kuraka Diego y canónigo en la catedral de Chuquisaca, permitió a varias familias indigenas usufructuar las estancias que él consideraba "partes integrales" de su hacienda Ccalla en la parroquia de Azángaro, sin obligar a estas familias a prestar sus servicios como yanaconas ${ }^{24}$. En

23 Ver además el expediente sobre el conflicto entre el Corregidor de Azángaro, Lorenzo Sata y Subiria, y el Cacique de Azángaro, Diego Choquehuanca, 1 de diciembre 1782 - 3 de enero 1783, ANB, Materias sobre Tierras e Indios, EC año 1783, no. 76; y el pliego de servicio de los Choquehuancas, ANB, Materias sobre Tierras e Indios, EC año 1782 , no. 57.

24 Sólo en 1870, en una fase de rápida expansión de la hacienda, los descendientes de Choquehuanca reclamaron la tierra de los 
otras palabras, aquí, un hacendado poderoso elige no incorporar a un número de familias como yanaconas, $e$ incluso renuncia al control temporal sobre algunas partes alejadas de su hacienda.

A pesar de ello, para los campesinos indígenas más pobres, los forasteros $y$ algunos hijos de los originarios, el acceso a la tierra y con ello su supervivencia continuó siendo precaria durante el resto del periodo colonial. Un número creciente de ellos abandonó las comunidades en las que habían vivido por generaciones. En parte ésto fue consecuencia de una serie de calamidades. En los años posteriores a la rebelión, entre 1782 y 1784, la parte norte del Altiplano se vió golpeada por una sequía que originó pérdidas en las cosechas, mayores reducciones de los rebaños de ganado $y$, en consecuencia la muerte y hambruna de mucha gente. Aún en 1784, más de un año después de la pacificación de la región, varios alimentos básicos, como el maíz, la harina $y$ todo tipo de legumbres eran tan escasos en el Collao que sus precios fueron los más altos que los habitantes de la región recordaban haber pagado.

A medida que la comida se hacía escasa, los campesinos buscaron oportunidades para ganar unos cuantos reales a través del comercio menor, trabajando como sirvientes o asistiendo a los viajeros en los caminos (Sahuarara, 1944:12 y 15 pie de pág. 37) ${ }^{25}$. El nuevo

descendientes de aquellas familias campesinas indígenas; ver el interdicto de adquirir del fundo Caluyo-Oque-Chupa, 3 de setiembre 1920. Archivo Judicial de Azángaro. Santamaria (1979:18:72:589) ha reportado que en las haciendas de Larecaja que producían maíz, en la ceja de selva de lo que hoy es Bolivia, inmediatamente adyacente a Puno, el número de yanaconas declinó entre 17 y $44 \%$ en las dos últimas décadas del siglo XVIII.

25 David Cahill ha sugerido que existe evidencia de sequía $y$ carestía de alimentos en el Altiplano desde 1780, lo cual echaría una importante luz sobre la rebelión de Túpac Amaru. Comunicación personal, febrero 1989. 
siglo no trajo consuelo. Una epidemia de angina en 1802-1803 mató a la décima parte de la población de la provincia $\mathrm{y}$, desde 1810-1811, las guerras de la independencia significaron reclutamientos masivos de los indígenas de Azángaro, mayormente por parte de los realistas. En conjunción con las duras heladas a todo lo largo del Sur del Perú, en 1814 y 1816, las disrupciones de las campañas militares trajeron déficits de alimentos tan severos que, de acuerdo a José Domingo Choquehuanca, las calles y la campiña de Azángaro estaban llenas de cuerpos de personas muertas por hambre (Choquehuanca, 1833:57 y 59$)^{26}$.

Pero la 'vagancia', como las autoridades contemporáneas llamaban a la creciente movilidad de la población indígena ${ }^{27}$, tuvo además causas estructurales. Durante las negociaciones de Diego Cristóbal Túpac Amaru con el Mariscal del Valle sobre un perdón general a fines de 1781, "los habitantes de Azángaro se vieron tan desesperanzados cuando supieron que los corregidores estaban volviendo" que muchas familias partieron hacia los escarpados del este de los Andes en Carabaya y Apolo (actual Bolivia) con su ganado y sus pertenencias (Fisher, 1966:358). La fuga hacia los límites de la región colonizada por los españoles siempre había sido un método de los indígenas del Altiplano y de los valles interandinos para evadir gravámenes demasiado pesados impuestos por

26 Para el reclutamiento de los indígenas de Azángaro, que ya se estaba dando en la primera fase de las guerras de la independencia, ver "Expediente formado a consecuencia de la representación que los Indios de Pupuja hacen ante la Justicia mayor de Azángaro para no volver a ser alistados para la expedición y dicho Justicia Mayor lo dirige original a la Excma. Junta Provincial", Cusco, 9 de octubre 1813, BNP, Colección de Manuscritos, Ms D 515.

27 La mayoría de los intendentes pasó decretos en contra de la vagancia. El intendente de Puno, Quimper, en su Bando de Buen Gobiemo del 30 de diciembre 1806, impuso un castigo de un mes de trabajo público a los vagos. Ver J. Fisher (1970:171). 
las autoridades coloniales. Algunos funcionarios de la Corona hacía tiempo que habían expresado su temor de que los abusivos repartos de bienes, la creciente imposición de impuestos de la Corona y los derechos de la Iglesia indujeran a muchos indígenas a retirarse hacia "las naciones bárbaras e infieles" 28 .

Pero existió otra, y probablemente más frecuente expresión de la "vagancia" entre los campesinos en el Altiplano: invasión precaria de tierras subutilizadas. En su descripción del Obispado del Cusco en 1790, en el cual el partido de Azángaro se encontraba al extremo sur, Pablo José Oricaín (1790:VI:331) describió este fenómeno con dramático detalle:

"No menos doloroso es el que muchos indios anden desviados por las mas escarpadas y áridas cerranías, comboiando sus familias y ganados, con el pretesto de mudar de pastos. Estos van cargando unos cortos palos, $y$ en donde encuentran a aguada, y rasonable pasto forman su media chosa, hasta que los naturales del lugar medio les obliguen a cualquier cervicio ó pención; que luego que advierten alguna formalidad desarman la chosa, y se mudan a otra jurisdicción, y así, se trasponen de un lugar a otro".

28 Precisamente ésto había preocupado al Virrey Amat a principios de la década de 1770 (ver su Memoria de Gobierno:193-4); ver también Kubler (s.d.:336-9) quien sugiere que la no llegada de oficiales coloniales y de los encargados de los censos y las retasas a lugares geográficamente remotos, explica en parte la caída de la población indígena frente a aquella registrada en los dos primeros siglos de la era colonial. Durante las décadas de 1780 y 1790 los mitayos de Azángaro se quedaron en Potosí luego de que su periodo de trabajo había terminado y establecieron un pequeño comercio de cebo a partir de su provincia de origen; esto a pesar de nuevos decretos que obligaban a los mitayos a volver a sus comunidades para prevenir cualquier futura merma de la escasa población rural (ver Tandeter, 1980:Ill:6:35) 
Un creciente número de forasteros y de hijos de originarios sin tierra $O$ con tierras insuficientes en las reducidas comunidades tomaron posesión precaria de los pastos no utilizados plenamente por sus poseedores. Estas tierras podian ser consideradas por las comunidades como de su propiedad, pero la Corona las consideraba baldías. Podía tratarse, asimismo, de tierras de haciendas recientemente formadas por terratenientes, kurakas o parroquias, subutilizadas y con títulos inciertos. El uso precario de tierras hizo que los campesinos más pobres pudieran escapar, aunque sobre bases inciertas, de las dos condiciones que más seriamente amenazaban su subsistencia: su carencia de tierra y la pesada carga de impuestos y derechos. Este tipo de "vagancia" no necesariamente significaba la separación de la comunidad a la cual los "invasores" pertenecían.

El debilitamiento de varios sectores de la élite colonial de la sierra sur desde principios de la década de 1780 debe haber disminuído el control sobre el campesinado indígena en términos de fuerza de trabajo, a pesar de los severos decretos anti-vagancia de las autoridades. Con la abolición de los repartos de mercancías por los corregidores, continuados sólo en una escala menor y con menos regularidad por los subdelegados, uno de los mecanismos más poderosos para obligar a los campesinos a trabajar fuera de sus comunidades o vender productos a comerciantes españoles había dejado de ser efectivo. El hecho de que la abolición de repartimientos conduciría a una menor producción y acceso a la mano de obra para beneficio de los hacendados, comerciantes, caciques y sacerdotes, fue precisamente la preocupación que apresuró al Visitador Escobedo a abogar por el reinicio del comercio autorizado con los indígenas bajo el eufemístico rótulo de "socorros". Este plan, característico del clima de las políticas en las décadas posteriores a Túpac Amaru, fue abandonado por temor a que condujera 
a nuevas revueltas (Fisher, 1970:88-9). La política de la Corona tuvo que maniobrar entre la Scylla de una extracción de excedente demasiado pesada, que había llevado al abandono total o parcial de los indígenas del orden colonial, y la Charybdis de limitar tales extracciones demasiado severamente, lo cual permitiría al campesino mayor autonomía, basada en la subsistencia doméstica y los intercambios recíprocos, en detrimento de los intereses de los principales constituyentes del régimen colonial en los Andes rurales, las élites provinciales.

En las críticas condiciones surgidas a inicios de la década de 1780, la Corona se sintió forzada a encontrar una salida para solucionar el dilema. Las políticas ahora estaban orientadas a establecer un nexo monetario directo más fuerte entre el campesinado indígena y la Corona y a limitar la extracción de excedentes de las élites provinciales. Mientras que el peso de los repartimientos y las extracciones por los caciques fueron reducidos, los pagos de tributo en el Norte del Altiplano se incrementaron notoriamente, especialmente en la segunda mitad de la década de 1780 (ver Cuadro I). Estos incrementos sólo podian ser parcialmente atribuídos al crecimiento de la población indígena: de acuerdo a las retazas de tributo, la población indigena de Azángaro creció en un poco probable $250 \%$ entre 1754 y mediados de la década de $1820^{29}$, mientras que el tributo depositado en las arcas distritales se multiplicó en 15 veces. La explicación está en los mejorados y más sistemáticos métodos de recolección del tributo, un esfuerzo que ya había comenzado en la década de 1750, pero que culminó en la década de 1780 , cuando los alcaldes y los recaudadores de tributo en muchos casos reemplazaron a los kurakas en esta

29 Las retazas de mediados de la década de 1750 pueden haber sido sobreestimadas $y$, por lo tanto, la tasa de crecimiento de la población durante los siguientes setenta años puede no haber sido tan fantásticamente alta. Comunicación personal de D. Cahill, febrero 1989. 
responsabilidad. Los subdelegados que sustituyeron a los corregidores como las más altas autoridades en los partidos, tenían un agudo interés personal en maximizar las recaudaciones de tributo, ya que ellos se quedaban con el $3 \%$ de los tributos pagados en su provincia. No era una mera coincidencia que los pagos de tributo se incrementaran dramáticamente precisamente durante la década posterior a que el comercio obligado con los indigenas hubiera sido proscrito y el comercio legal en el Altiplano -en contraste con otras áreas del Perú- se hubiera estancado, como se evidencia por el nivel casi uniforme de los recibos de alcabala.

A partir de la década de 1780 miembros de todos los grupos sociales en el Altiplano buscaban redefinir sus gestiones económicas y sus relaciones, mientras que los perfiles del nuevo orden continuaban siendo borrosos. Los dueños de haciendas, kurakas, sacerdotes $y$ comerciantes españoles ingresaron a una fase de dificultades $e$ inestabilidad, ya que su comercio con el Alto Perú se redujo, su control sobre la economía campesina se debilitó y las medidas borbónicas bloquearon crecientemente la consolidación de sus haciendas.

Los campesinos del Altiplano deben haber experimentado las décadas entre 1780 y comienzos de 1820 como un perplejo "claroscuro", algo que van Young ha observado para Nueva España (1986:64-90). Para ellos esta fue una era que trajo una creciente interferencia burocrática en asuntos de la comunidad tales como la elección de los kurakas y la distribución de los pastos y las tierras de cultivo. Con el consentimiento de los administradores coloniales las propiedades que pertenecían a las antiguas cajas de comunidad a menudo fueron ocultadas por los mestizos y criollos que las habían arrendado ${ }^{30}$ y la recolección del tributo entre aquellos

30 Informe de Pedro Antonio Zernadas Bermúdez, Oidor de la Audiencia de Cusco y presidente de la Comisión de la Caja General de 
campesinos que no habian abandonado sus comunidades permaneció a un nivel muy elevado hasta inicios de las guerras de la independencia.

Sin embargo, de alguna manera, la multifacética crisis que arrasó con tanta fuerza en 1780 reforzó la autonomía del campesinado del Altiplano. Los repartos de bienes, tan cruciales para el orden colonial por lo menos desde fines del siglo XVII, se redujeron a una sombra de lo que habían sido $y$ a los agentes privados les fue más difícil servirse de la economía campesina para su propia ventaja y ganancia. La ambigua política agraria de los Borbones finalmente detuvo la consolidación de haciendas recientemente formadas y la incorporación de más tierras de las comunidades. Mientras que la política de la Corona de limitar la tierra comunal a una extensión específica por unidad doméstica había llevado a serios déficits de tierra al interior de las comunidades, el bloqueo de la expansión de las haciendas favoreció indirectamente la precaria apropiación de esas tierras por parte de los campesinos más pobres mediante la invasión. $\mathrm{El}$ intento de lograr un mayor control del campesinado a través de las autoridades coloniales tuvo serios límites: no se logró que se retiraran de las tierras que la Corona consideraba pertenecian al dominio real o a propietarios privados o a la Iglesia $y$, al menos durante todo un año, (1812) del "cautiverio napoleónico" de la monarquía española, los

Censos de Indios del Cusco del 31 de diciembre de 1791, titulado "Razón de los principales censos perdidos, unos por haberse arruinado las fincas sobre que estaban impuestos, otros por haberse oblado, y no vuelto a imponerse, $y$ otros por haberse perdido en los pleitos de concurso de acreedores y demás seguidos contra las fincas en que estaban impuestos", BNP, Colección de Manuscritos, Ms C 1274. De acuerdo a Zemadas, propiedades comunales valorizadas en 50,489 pesos estaban totalmente perdidas y propiedades valorizadas en 120,138 pesos estaban en el limbo y la renta anual no se había aplicado a éstas por años; los derechos de arriendo sólo se estaban pagando sobre las propiedades valorizadas en 29,783 pesos. 
indígenas de Azángaro fueron lo suficientemente fuertes como para sacar partido de la nueva legislación, para rehuír toda recaudación de impuestos ${ }^{31}$.

Por lo tanto, sería demasiado simple decir que el campesinado del Altiplano fue derrotado en la rebelión de Túpac Amaru. Los campesinos no necesitaban una victoria militar para conquistar muchos de sus objetivos. Una rebelión es la forma más extrema de renegociar los términos bajo los cuales los campesinos podían perseguir la reproducción de su propia economía y cultura comunal. Las rebeliones campesinas que se llevaban a cabo en regímenes feudales, patrimoniales $\mathrm{u}$ otras formas tradicionales raramente buscaban derrotar a ese régimen para siempre. $\mathrm{Si}$ a través de la rebelión pueden incrementar el costo de represión y coerción de manera considerable, habrán obtenido un considerable éxito en su renegociación con los grupos dominantes ${ }^{32}$. Precisamente esto fue lo que sucedió a principios de la década de 1780 en el sur de los Andes. Las élites provinciales sufrieron fuertes pérdidas físicas y materiales y su cohesión interna se vio seriamente comprometida. El costo para adquirir tierra y fuerza de trabajo indígena mediante la coerción se incrementó considerablemente. Lo que hizo que la situación empeorara para los hacendados y comerciantes españoles fue el debilitamiento gradual del mercado para los productos pecuarios, en la medida en que los obrajes del Cusco

31 José Victoriano de la Riva, Contaduría General de Puno a Mariano Escobedo, Justicia Mayor de Azángaro, Puno 27 de mayo de 1813 , BNP, Ms D 456, sobre el fracaso del subdelegado en la recolección de la "contribución provisional" en la provincia, luego de que las Cortes de Cádiz hubieran abolido el tributo en 1812.

32 Debo la precisión y la claridad de estas ideas a John Coatsworth, quien las formuló en una conferencia llevada a cabo en el seminario para graduados sobre historia latinoamericana de Joseph Love, Universidad de Illinois, Urbana-Champaign, 7 de marzo 1989; también se encuentran ideas similares con respecto a los aspectos agrarios de la revolución mexicana en el artículo de A. Knight (1985:4:2:23-5). 
iniciaron una debacle que culminaría en la década de 1840. Enfrentada a una insurrección que involucraba a decenas de miles de campesinos la Corona tenía que reconsiderar sus prioridades. Resguardar el frágil lazo con el campesinado indígena era más importante que poner en práctica medidas agrarias ilustradas. Se tenía que hallar un balance entre mantener este "contrato colonial" subyacente y no perder la lealtad de los verdaderos constituyentes coloniales de la Corona, la élite administrativa y económica conformada por criollos y mestizos. El camino hacia el liberalismo de la política agraria en el Perú, que se había acelerado en España durante la década de 1790 , fue bloqueado debido a la relación de fuerzas en las colonias.

El pensamiento de los Borbones con respecto a la propiedad rural se vió estorbado por contradicciones insuperables: de un lado, aspiraba a lograr una amplia distribución de las propiedades de tierras como la vía más prometedora para una mayor producción agrícola; de otro, por necesidades fiscales y de orden social, los Borbones nunca pudieron realmente abandonar la peculiar relación entre la Corona y el campesinado indígena que heredaron de los Habsburgos. Inclusive a inicios del siglo XIX ellos dependian del campesinado para la solvencia fiscal de la colonia y el acceso regulado a la mano de obra indígena. A cambio, ellos tuvieron que garantizar al menos de manera mínima la continuidad de las jerarquías sociales y las costumbres al interior de las comunidades indígenas, aun cuando, como hemos visto, las políticas de la Corona se volvieron más y más contradictorias a partir de 1780. Consecuencia de esta relación especial, simbolizada por el nexo del tributo, fue que los Borbones no podían cambiar patrones establecidos de usufructo de las tierras comunales. Ello podría recortar la capacidad o la disposición de los originarios a pagar tasas más altas y sostener cargos onerosos en sus comunidades. Por más que los Borbones estaban interesados en una amplia 
distribución de la tierra, no encontraron una manera para convertir a los campesinos indígenas en propietarios libres con el título completo de sus tierras, de acuerdo a los conceptos liberales, sin al mismo tiempo deshacer esa relación especial, la base social y fiscal imprescindible de su dominio colonial.

El Virrey José Fernando Abascal y Sousa, tan crítico del liberalismo como pragmático con respecto a los cambios en las opciones de política, percibió claramente la relación entre el status especial del indígena y los límites de la reforma agraria. Sólo luego que las liberales Cortes de Cádiz (muy a su disgusto) habían abolido el tributo y la mita en $1812 \mathrm{y}$, por lo tanto, socavado críticamente la estabilidad del régimen colonial, Abascal consideró seriamente una distribución de tierras a las familias de mestizos empobrecidos $y$ sin tierras, cuya condición achacaba al extendido bandolerismo y crimen. En su memoria de 1816 sugirió que:

"la propiedad de esas mismas tierras [de los originarios], que corresponden por derecho de reversión al Estado, y sus muchos sobrantes son un medio que se presenta oportunísimo para colocar infinitas familias de Mestisos, redimiéndolos de la miseria en que han vivido..."33.

33 Abascal, Memoria de Gobierno (1:175-80). Probablemente la palabra originarios en este contexto se refiere a la población autóctona. La Corona había reintroducido el tributo en 1815; pero puede ser que este no haya sido implementado en el momento en el cual Abascal escribió su informe. En el quinquenio que faltaba para que las tropas patriotas ocuparan Lima la recolección de éste nunca recobró los niveles anteriores a 1812. Para la posición proto-liberal sobre la propiedad agraria en el Perú a principios del siglo XIX, ver el informe sobre la Hacienda Pública de José Baquijano y Carrillo (CDIP, 1976:1:3:585). Por lo menos, se trata de una burda simplificación cuando Iwasaki sugiere que "Olavide no tuvo influencia alguna en el Perú", en cuanto al reformismo agrario (1987:146). 


\section{NILS JACOBSEN}

Pero es dudoso que el régimen colonial hubiera podido llevar a cabo una reforma agraria de este tipo sin que posteriormente se desintegrara su orden jerárquico y su fibra social, equivalente a la subversión del régimen colonial mismo.

\section{IV}

La explosiva mezcla de desalentadoras condiciones para las haciendas ganaderas, la posición fortalecida del campesinado y los decretos reformistas liberales $y$ las leyes del Congreso durante la década de 1820 tuvieron un gran impacto en la tenencia de la tierra entre el campesinado del Altiplano. Inicialmente, la ignorancia con respecto a las diversas realidades en el campo peruano entre los seguidores de Simón Bolivar limitó la efectividad de los serios esfuerzos que ellos realizaron. Al final, una ley que estableció un curioso balance entre los conceptos liberales de propiedad y el reformismo ilustrado borbón, contribuyó enormemente a dar forma al régimen de propiedad rural del país en las décadas siguientes.

La abolición del tributo decretada por José de San Martín el 27 de agosto de 1821 fue el impulso de las primeras medidas agrarias tomadas por el régimen republicano, ya que -al igual que las Cortes en 1812cortaban el nexo entre la hacienda pública y la supervivencia de la comunidad indígena corporativa. El 8 de abril de 1824, cuando el Altiplano aún se encontraba bajo el control realista, Bolivar desde Trujillo decretó que todas las tierras del estado fueran vendidas a un tercio por debajo de su valor tasado. Los indígenas serían considerados dueños de las tierras que en ese entonces poseían. El decreto además ordenaba la distribución de las tierras de la comunidad a aquellos indígenas que en ese momento no poseían tierra, de tal manera que "ningún indígena permaneciera sin su respectiva parcela". Los 
excedentes de tierras de las comunidades deberian ser vendidos bajo las mismas condiciones que las demás tierras estatales [ex-realengas]. En cada provincia se nombraría a visitadores para que llevaran a cabo la distribución de la tierra "con la exactitud, imparcialidad y justicia necesarias" (Valdez de la Torre, 1921:145-6; Basadre:I:170-1).

La primera incursión de Bolivar en el laberinto de la estructura de la propiedad rural en el Perú perseguía un doble objetivo: usar la venta de las tierras de las haciendas por debajo de su valor como un medio seguro para recolectar el dinero que se necesitaba urgentemente para la campaña libertadora $e$ incrementar la producción agrícola a través de la emergencia de una clase industriosa de labradores indigenas y mestizos. Esta fue la más liberal, pero también la menos realista de las principales leyes agrarias de la década de 1820. No estableció ninguna restricción a la reventa de las tierras distribuídas, cumpliendo asi con el precepto de las nociones liberales sobre la tierra, de acuerdo al cual sólo su libre circulación podría asegurar su óptima utilización. Pero Bolivar $y$. sus consejeros no se dieron cuenta que la venta de tierras estatales, aun a un tercio por debajo de su valor de mercado, efectivamente excluía a aquellos indigenas $y$ mestizos pobres $y$ sin tierras, a quienes esta venta debía beneficiar. En muchas provincias, además, al igual que en el Altiplano, no quedaban tierras de comunidad de libre distribución, una vez descontadas aquellas parcelas que debían ser entregadas a sus poseedores. Finalmente, al encargarse la distribución a los visitadores nombrados en las provincias, sólo las élites locales $y$ sus clientelas se beneficiarian de cualquier distribución. En síntesis, era imposible para las débiles autoridades insurgentes lograr una reforma agraria que, de una sola vez, produjera ingresos para el estado, ampliara significativamente la distribución de la tierra y asegurara su libre circulación. 
A medida que Bolivar y sus consejeros iban comprendiendo la estructura agraria peruana, fueron debilitando los contenidos (filosóficamente) liberales de sus políticas agrarias y se movieron hacia las posiciones reformistas de los Borbones de mediados del siglo XVIII. Un decreto del 4 de julio de 1825 estipulaba límites en cuanto a la cantidad de tierra de la comunidad que se distribuiría entre los indígenas sin tierras. Los caciques recibían una cantidad de tierra considerablemente mayor que los comuneros. Significativamente, las propiedades de los caciques y los alcaldes recaudadores de tributos, basadas en su cargo (tierras de oficio), que habían causado serios conflictos durante las últimas décadas coloniales, no serían reconocidas, mientras que sí lo serían aquellas de los caciques de sangre, los descendientes de la nobleza andina. Los indígenas que se habían convertido en dueños de tierras de la comunidad mediante el decreto de abril de 1824 no podrían venderlas antes de 1850. El decreto también buscaba reforzar el control del gobierno central sobre la selección de los comisionados de tierra provinciales, obligando a las autoridades departamentales a remitir una terna de candidatos (Valdez de la Torre, 1921:1478; Davies:21). Mientras que por una última vez se favorecía a los caciques basándose en su posición social, mas que en privilegios que surgían de sus cargos, Bolivar procedió ese mismo día (4 de julio de 1825) a eliminar el título de cacique (Dancuart y Rodríguez, 1902-26:I:272). La dilusión de los contenidos liberales en la legislación agraria se hizo más marcada durante el siguiente año. Debido a la creciente presión fiscal, en agosto de 1826 el Consejo de Gobierno, en el cual reformistas borbones como Hipólito Unánue y José de Larrea y Loredo mantuvieron posiciones prominentes, reintrodujeron el tributo indígena bajo la eufemística denominación de contribución de indígenas, una medida que de otra manera replicaba expresamente las modalidades del impuesto que la precedía. La inevitable consecuencia en el programa agrario se dio 
inmediatamente después, cuando en diciembre de 1826 Bolivar instruyó a las autoridades provinciales a que dieran preferencia en la distribución de las tierras de la comunidad a los originarios, aquellos que pagaban la tasa completa de la contribución de indígenas, dejando de lado a los forasteros (Dancuart y Rodríguez, 1902-26:I:277-8; Valdez de la Torre, 1921:148).

Así estaban las cosas hacia diciembre de 1826. Se había retirado cualquier privilegio legalmente establecido de las comunidades indígenas. Pero se reconocía la existencia de una estratificación basada en el prestigio social y la riqueza, al privilegiar a los ex-caciques y los originarios. La escasez de tierras comunales en muchas regiones del país hizo volver la mirada hacia la práctica de los Borbones, aquella de distribuír cantidades estrictamente limitadas de tierras comunales. Así se replicaban las jerarquías sociales al interior de las comunidades, aunque con la decisiva diferencia de que las parcelas ahora iban a ser retenidas en propiedad absoluta. Sin embargo, estos principios de distribución al interior de las comunidades chocaban con el principio más liberal del decreto agrario original de 1824 que se había conservado, es decir, que cada indigena sería dueño sin contradicción de cualquiera que fuera la tierra que tuviera en ese momento. Esta provisión no podía ser aplicada, entonces, al interior de las comunidades, sino sólo a las tierras que los indígenas poseían fuera de las comunidades, a menudo bajo las precarias condiciones que hemos discutido para la última parte del periodo colonial. Más aún, los bolivarianos, al imponer una prohibición de 25 años a la venta, ahora habian retirado el concepto liberal clave: el de la libre circulación de todas las tierras que los indígenas iban a poseer en dominio absoluto, dentro o fuera de los parámetros legales de la comunidad. Sospechando que los campesinos indigenas no podrian competir con poderosas élites provinciales en un mercado libre de tierras, se sacrificaba la noción liberal de libre circulación para 


\section{NILS JACOBSEN}

salvaguardar el antiguo objetivo de los Borbones de una amplia distribución de la tierra productiva (Piel, 1975:I:2812).

Sin embargo, como los bolivarianos to entendieron completamente, especialmente luego de la triunfante gira del Libertador por la sierra sur a mediados del año de 1825, la realización de cualquier parte de su reforma agraria dependía de las constelaciones de poder en las provincias. Al buscar, además, la redistribución de las tierras de la comunidad, necesitaban confiar en la voluntad de las autoridades locales para llevar a cabo estas medidas "con imparcialidad y justicia". Y es aquí donde parece que las medidas de la reforma agraria de Bolivar tropezaron $y$ se detuvieron completamente. Los visitadores $y$ las comisiones de tierras en la provincia, fracasaron en llevar a cabo la medición $y$ registro de las tierras de la comunidad o cometieron "el más pernicioso abuso" al otorgar de manera injusta títulos de tierra a sus favoritos. Según el parecer del gobierno central en Lima, las comisiones provinciales carecían de la autoridad "para librar títulos de propiedad, posesión, ni autorizar ó corroborar los que amparen a los tenedores, y mucho menos a repartir tierras, ni hacer composiciones; pues sus facultades son meramente informativas" 34 . En agosto de 1827 una resolución del Congreso reiteraba que ninguna tierra de las comunidades debería venderse hasta que las comisiones de tierra hubieran entregado sus informes al gobierno central (Valdez de la Torre, 1921:149). Así, cada vez fue más claro que para lograr algo con respecto al problema agrario, las autoridades provinciales, estrechamente relacionadas a las élites, tenían que ser retiradas del proceso.

34 Circular de febrero de 1827, citada por Valdez de la Torre (1921:152). 
La ley que tendría un impacto duradero en el patrón de tenencia de la tierra, por lo menos en Azángaro, fue aprobada por el Congreso el 27 de marzo de 1828. Nuevamente declaraba que los indígenas, y esta vez también los mestizos, eran los propietarios de las tierras que ocupaban en ese momento sobre la base de periódicas redistribuciones de las tierras comunales o -con respecto a las tierras fuera de las comunidades, como lo establecían las autoridades de los Borbones- "sin contradicción", es decir, sin que otros litigantes se presentaran para disputar su posesión. La única limitación en su derecho de vender esta tierra ahora consistía en la estipulación de que ellos tenían que saber leer $y$ escribir. Los indigenas $y$ los mestizos sin tierras iban a recibir parcelas de las sobrantes tierras estatales, una vez que las juntas departamentales hubieran recogido la información estadística correspondiente. En caso de que existieran tierras excedentes luego de esta operación, éstas serían asignadas a las escuelas, como fuente principal de sus ingresos (Dancuart y Rodríguez, 1902-26:II:136; Basadre, 1968:I:227).

Esta ley debe haber circulado por los más remotos lugares del Perú durante las décadas que siguieron. Los campesinos indigenas la consideraron como la base de su derecho a una estancia. Cuando, por ejemplo, el 10 de mayo de 1859 María, Carmen y Sebastián Carcausto vendieron su estancia Ccatahui Sencca, en el ayllu Urinsaya, distrito de Azángaro, a Juan Paredes ellos declararon que habían heredado la tierra de su padre Andrés “... a quien la ley del año 28 lo encontró en posesión y desde ese tiempo nosotros somos los dueños (de la estancia)" 35 .

La diferencia crucial entre la ley de 1828 y las medidas bolivarianas precedentes está en la influencia que ahora los visitadores o cualquier otra autoridad provincial 
podian ejercer sobre su implementación. Ahora otorgar derechos de propiedad a cualquier tierra que los indígenas o los mestizos poseyeran, procedería inmediatamente, independientemente de $y$ previo a cualquier registro $o$ avalúo de tierras hecho por las autoridades. La distribución de tierras de la comunidad o de otras tierras estatales a los indigenas y mestizos sin tierrras ocurría de manera separada de y subsecuente a la mera extensión de los derechos de propiedad a cualquier tierra poseída en usufructo o de manera precaria.

Fue esta entrega de títulos de propiedad la que habría de tener los efectos de una reforma agraria en el Altiplano. Aparte de afirmar derechos a las tierras de la comunidad, reforzaba el título de los campesinos a aquellas tierras -fuera de los estrechos límites de las comunidades borbónicas- que ellos ocupaban y trabajaban de manera precaria, pero que habian estado en el limbo durante las últimas décadas del régimen colonial: tierras que habían sido reclamadas por hacendados, kurakas o sus sucesores, los recaudadores de tributos, o la Iglesia, pero que la Corona desde la década de 1780 se había rehusado cada vez más a otorgar en dominio absoluto a través de composiciones; o tierras que nunca habían sido reclamadas como propiedad por los miembros de la élite colonial y habian sido consideradas por la Corona como tierras realengas, pero que habitualmente estaban siendo ocupadas por forasteros $y$ otros que no tenían suficientes tierras en las comunidades. Frente a la debilitada posición de los terratenientes en Azángaro, la ley de 1828 aclaró de un sólo golpe la paradójica condición de fines de la colonia: escasez de tierra entre los campesinos en una era de abundancia de tierra y bajas densidades poblacionales. El gobierno republicano cesó en sus intentos de desalojar a los campesinos de las tierras que ellos ocupaban en 1828, como repetidamente habian hecho los Borbones al declarar que todas las tierras de la comunidad y muchas de las tierras trabajadas de manera precaria por los 
campesinos fuera de las comunidades eran realengas. Los hacendados al igual que la Iglesia, al menos por el momento, habían perdido la batalla legal sobre una gran parte de la tierra que ellos habian intentado integrar a sus haciendas en las décadas anteriores a 1780 y, como hemos visto, en algunos casos más tarde.

La ley de 1828, empero, fracasó de la misma manera que las medidas bolivarianas en lo referente a la redistribución real de la tierra. En Azángaro "no ha habido un palmo de tierra que no hubiese reconocido poseedor precario [...] y por todo referido no tiene lugar el artículo 2 de la ley citada [referente a la distribución de las tierras excedentes estatales]" (Choquehuanca, 1833:72). Las autoridades provinciales ingeniaron artificios para vender ilegalmente o reafirmar mediante la composición algunas tierras estatales, consideradas sobrantes o tierras de oficio luego de la extinción del cargo de cacique $y$ de las medidas bolivarianas previas sobre la tierra (Choquehuanca, 1833:72). Pero no puede haber ninguna duda de que en el Altiplano los mayores beneficiarios de la ley de 1828 fueron las miles de familias campesinas que se encontraban en posesión precaria de tierras fuera de las comunidades desde fines del siglo XVIII. Por lo tanto, la ley consolidó legalmente un equilibrio temporal entre los campesinos y las haciendas en el norte del Altiplano. Cualquier futuro intento de tomar control sobre las tierras de los campesinos no podría basarse en reclamos de títulos coloniales. En las décadas posteriores a 1850 , con un rápido desarrollo del mercado de tierras, los notarios, de manera rutinaria, reconocían los títulos de propiedad de los campesinos basados en la ley de 1828.

Esto no refuta la noción de que las leyes agrarias de la década de 1820 facilitaron legalmente el asalto a las tierras indigenas a fines del siglo XIX y comienzos del siglo XX. Pero demuestra que las medidas de la década de 1820 no constituyeron simplemente la aplicación 
desacertada o inclusive interesada de nociones liberales abstractas de propiedad. Las metas de los reformistas agrarios de la década de 1820 -incrementar las rentas públicas, una distribución amplia y relativamente igualitaria de la tierra, al igual que su libre circulación- no podian ser logradas de una sola vez. En las batallas políticas sobre la definición de una política realista, sostenidas entre varias facciones de Lima y los grupos de la élite y las autoridades provinciales, el "impulso liberal" fue templado y modificado de tal manera que al final las medidas agrarias mostraron tanto un reformismo continuista borbón, como nuevos puntos de partida liberales. El efecto sobre el desarrollo de un mercado de tierras idealmente libre que tendría el reemplazo de confusos derechos de uso y tenencia precaria de la tierra por títulos individuales de propiedad, sólo se haría aparente luego de $1850 \mathrm{y}$ ciertamente fue de importancia secundaria para los reformistas de la década de 1820. Sus principales preocupaciones se dirigían a asegurar la recolección de ingresos para el fisco entre los pequeños propietarios indígenas y mestizos y estimular la producción agrícola a través de una amplia distribución de la tierra. La renovada confianza en un impuesto personal para los indígenas trajo consigo el reconocimiento de jerarquías sociales en las comunidades indígenas, aunque sin los privilegios corporativos coloniales y los poderes asociados a los cargos $^{36}$. Ciertamente, los intereses fiscales llevaron a los primeros gobiernos republicanos a vigilar la preservación de las tierras indígenas. Tan tarde como en 1847, justamente dos o tres años antes del explosivo aumento de ingresos a raíz del guano, Manuel del Río, Ministro de Hacienda durante el primer gobierno de Ramón Castilla,

36 Para una interpretación similar de la legislación sobre la tierra a principios de la república en Bolivia, que inclusive enfatiza el retorno al "status quo ante" luego del fracaso de las nociones liberales originales, ver Langer (1988:14:59-95). 
se pronunció por una ley que sólo permitiría que los indígenas vendan sus tierras a otros indígenas. El temía que un extendido uso del derecho de los indígenas de vender su tierra libremente, llevaría a una seria caída en la recaudación fiscal, ya que los indígenas sin tierras o con muy poca tierra sólo pagarían la mitad de la contribución de indigenas ${ }^{37}$.

Los críticos del liberalismo peruano del siglo XIX han afirmado que los efectos de las leyes agrarias llevadas a cabo durante la década de 1820 consistieron en un ciclo inmediato de toma de tierras por parte de los grandes terratenientes criollos $^{38}$. Sin embargo, a pesar de que la evidencia es escasa, entre fines de la década de 1820 y la década de 1850 la transferencia de tierra del sector campesino de Azángaro al sector de los hacendados parece haberse dado a un ritmo relativamente lento. La transferencia de tierra campesina hacia el sector de hacendados de Azángaro durante la década de 1850 puede muy bien ser caracterizada "de goteo"39. No existe razón para creer que durante las dos décadas precedentes la expansión de la hacienda se diera a un ritmo mucho más dramático, particularmente dado al deprimido nivel del mercado de lanas durante la mayor parte de la

37 Ministerio de Hacienda. Memoria que presenta el Ministro de Hacienda del Perú al Congreso de 1847 (Lima:Imp.de José Masías, s.f.), pp. 3-4. Además, en 1834, el gobierno central instruyó a los subprefectos para que investigaran si, burlando la ley de 1828 , los indígenas que no sabían leer ni escribir habían vendido tierras. El prefecto de Arequipa había expresado su preocupación sobre las consecuencias de dichas ventas en la recolección de la contribución de indígenas. Ver la circular del prefecto Ramón Castilla a los cinco subprefectos del departamento de Puno, 5 de diciembre 1834, Instituto "Libertador Ramón Castilla", Archivo Castilla (Lima:Imp. de la Universidad Nacional Mayor de San Marcos), 1963, p. 183.

38 Ver, por ejemplo, Davies (sf:22); Sivirichi (1946:102); Mariátegui (1974:75).

39 La evidencia para esta afirmación se presenta en Jacobsen (1982:caps. V y VI). 
década de $1840^{40}$. Mientras que algunos de los primeros hacendados republicanos -Francisco Lizares en Muñani entre los más notables- expandieron sus propiedades en tierras campesinas, éstos eran casos aislados. Durante las primeras tres décadas republicanas los campesinos de Azángaro poseían sus tierras con menos desafíos y amenazas de desalojo, que las que habían enfrentado durante el último siglo de la era colonial ${ }^{41}$.

A menudo se ha asumido que la legislación de la década de 1820 abolió legalmente las comunidades (Davies, sf:21). Sin embargo, mientras que las reformas de la década de 1820 privatizaron legalmente toda tierra en posesión comunal, ninguna ley o decreto avanzó como para proscribir positivamente a las comunidades indigenas. Esta situación se prolongaría hasta fines del siglo XIX. Ni siquiera el código civil de 1852 abolió las comunidades; meramente siguió la ya bien establecida tradición legislativa de descuidar del todo a la institución (Sivirichi, 1946:210ff). A mediados del siglo XIX la comunidad indígena peruana se había convertido en "un patrimonio jurídico sumergido, vivo en el alma y en las costumbres de los campesinos, si bien invisible y extraño para la mentalidad formalista de los magistrados y de las autoridades..." (Basadre, 1968:III:1309).

Ya que el estado nacional había retirado su protección legal y cesado las funciones habituales que habían dado a todas las comunidades ciertas características

40 Macera (1974:CL) habla del "equilibrio" en el "conflicto secular entre las comunidades indigenas y las haciendas" que se había alcanzado a fines del siglo XVIII y continuó hasta la década de 1850.

41 Para una interpretación similar del desarrollo mexicano, ver Coatsworth (1974:54:48-71), Tutino (1986:cap. 6). Gonzáles (1977:1427) demuestra que muchos intentos de los gobiernos nacionales 0 provinciales $y$ de las autoridades locales de privatizar las tierras de la comunidad indigena en la región central de México antes de 1855 fracasaron ante la inaplacable oposición campesina. 
comunes durante la era colonial, la continua vitalidad de las comunidades indígenas ahora dependería principalmente de las circunstancias locales, como las relaciones de producción, el tipo de cultivos (particularmente el contraste entre la ganadería y la agricultura), el grado de producción para el mercado, las relaciones de poder entre los campesinos indígenas y la élite local o provincial, al igual que la cohesión al interior de las comunidades. Consecuentemente, desde la década de 1820 las comunidades indígenas en las distintas regiones del Perú pasaron por un proceso de creciente diferenciación, particularmente con respecto a la tenencia de la tierra ${ }^{42}$.

Mientras que en muchas partes del departamento del Cusco las tierras de la comunidad continuaron siendo distribuídas cada año y no fueron tratadas como propiedad privada en términos de herencia, en las provincias del Altiplano como Azángaro la ley de 1828 sí creó a un grupo de terratenientes campesinos, en base a tierras al interior de grupos de parentesco patrilineales que no eran coextensivos con los ayllus o las parcialidades. Aquí la propiedad comunal de la tierra fue reducida a un mínimo. Sin embargo, esto no significó la desaparición de las comunidades de Azángaro. En febrero de 1844, por ejemplo, la comunidad de Tiramasa acusó a un tal Juan Arpita ante el Juez de Paz de Azángaro por invadir las parcelas llamadas Moroquere, Calasacsani y Chijurani. Los representantes de la comunidad explicaron que "las tierras en cuestión pertenecen a la comunidad y son mandas en las cuales cada año en el momento propicio ellos plantaban sus cultivos... ". Arpita aducía que Chijurani era de su propiedad. El Juez de Paz arregló la disputa ordenando a

42 Valdez de la Torre (1921:159) detalla para principios del siglo XIX la gran variedad de sistemas de tenencia de la tierra que se encontraba en las comunidades indígenas en las diferentes partes del Perú y que iban desde una distribución periódica de todas las tierras comunales hasta la propiedad individual de todas las tierras. 
las partes, la comunidad y Juan Arpita, no transgredir la propiedad de cada cual. Se labró una zanja divisoria, la cual satisfizo a ambas partes ${ }^{43}$. La comunidad de Tiramasa, entonces, estaba lo suficientemente activa como para defenderse de las incursiones. La tierra en cuestión se usaba para parcelas de sembrío, las tan mencionadas mandas o levas de la comunidad; éstas continuaron formando el núcleo sobreviviente de la tierra comunal en las parcialidades y ayllus de Azángaro, hasta el siglo XX. Pero estas parcelas eran diminutas -no más de unas cuantas hectáreas- comparadas con las vastas tierras de pastoreo que a partir de los decretos de la década de 1820 habían llegado a ser consideradas como tierra privada de los grupos familiares de campesinos. La solidaridad de la comunidad, a nivel de las parcialidades, se ejercía principalmente en la defensa del conjunto de tierras de los comuneros hacia afuera, ó en asuntos no directamente relacionados con tierras; pero ya no primordialmente en su usufructo común.

Al describir el proceso gradual de privatización de las tierras comunales en el Perú, la mayoría de los autores reclaman que los pastos continuaron siendo propiedad comunal por más tiempo que los campos agrícolas ${ }^{44}$. Como hemos visto, en Azángaro ocurrió lo contrario. ¿Por qué el patrón de tenencia de la tierra de las comunidades evolucionó en este caso de una manera diferente a la de otras regiones del Perú? La respuesta a esta pregunta se encuentra en la base económica de determinadas comunidades. A medida que el concepto de propiedad privada penetra lentamente en las estructuras

43 REPA, año 1892, Meza (21 de Diciembre 1892, protocolorización notarial de los expedientes originales ante el Juez de Paz de Azángaro, Andrés Contreras, el 23 de Febrero de 1844).

44 Ver, por ejemplo, Valdez de la Torre (1921:159), donde hace este reclamo específicamente para las comunidades de Puno. 
de la comunidad tradicional, éste encontrará aceptación primeramente para aquel aspecto de la economía campesina que constituye su principal fuente de ingresos, particularmente si ésta los relaciona con la economía de mercado. El concepto de ganancia individual, que una interacción de largo plazo con el mercado fomenta, estimulará en el campesino el deseo de tener control exclusivo e irrevocable sobre la tierra, que le permite producir el excedente comercializable. La competencia sobre las tierras que se emplean en la producción de estos bienes será fuerte. Inversamente, aquellas tierras que son utilizadas para la producción de bienes que sirven sólo para el consumo de las familias campesinas estarán sujetas en un grado mucho menor a presiones de privatización, ya que no se otorgará un valor de mercado a los bienes producidos en ellas $y$, por lo tanto, el concepto de competencia individual por estos recursos tenderá a ser más débil. Por ello, en Azángaro los campesinos indígenas primero comenzaron a abandonar los patrones comunales de tenencia de la tierra sobre las tierras de pastoreo debido a que la cría de animales era la actividad económica familiar más importante. Así, la competencia por tierras de pastoreo fue fuerte entre los campesinos de la comunidad, mientras que las pequeñas parcelas agrícolas permanecieron bajo formas comunales de producción.

Este no es el lugar para discutir otros aspectos de la situación del campesinado del Altiplano durante las décadas posteriores a la independencia. Pero las evidencias sugieren que la presión de las élites sobre los campesinos $y$ sus recursos disminuyó o fue comparativamente inefectiva entre 1820 y 1850 . Los montos recaudados por concepto de la contribución indígena estuvieron por debajo del nivel de fines del período colonial; a pesar de que los mineros de la región intentaron revivir la mita minera, tuvieron serias dificultades para reclutar en las comunidades campesinas a los cerca de 1000 trabajadores para las 
minas que aún requerían para mantener sus lánguidas operaciones en la Cordillera de Carabaya, en la provincia de Lampa y en la mina Manto cerca a Puno. Los requerimientos de mano de obra de las haciendas ganaderas de Puno se estancaron a medida que los hacendados se encontraban agobiados por los crecientes costos de transporte y crédito, los deprimidos mercados regionales y la todavía insuficiente demanda de exportaciones de sus productos. Con la emergencia de estructuras de mercado más competitivas a través del surgimiento de ferias anuales $y$ del creciente rol de los comerciantes extranjeros, por varias décadas los campesinos fueron menos dependientes de las autoridades provinciales monopolistas, comerciantes y grandes hacendados para comercializar sus productos. El poder político gamonal todavía no estaba lo suficientemente consolidado antes de la década de 1850 para permitir una extracción de excedentes de los campesinos en el mismo grado que antes de 1780. Las enormes luchas internas entre las familias de la élite provincial por los beneficios que otorgaban los cargos oficiales, debido a las deprimidas oportunidades en el comercio y la ganadería, en algunos momentos permitieron a las comunidades formar alianzas con los gobernadores o inclusive con los subprefectos para detener las crecientes demandas de otros gamonales (Hunefeldt, 1989:7:2:367-401; Jacobsen, mss:caps. 2 y 4; para México: Tutino, 1986:cap. 6).

Sin embargo, el retroceso de las élites provinciales no necesariamente condujo a un creciente bienestar material, ya que los campesinos también fueron afectados por los menores precios de los textiles que producían domésticamente. La caída de la extracción de excedentes no había elevado el ingreso de los campesinos por encima de lo que puede ser llamado el nivel de subsistencia. Una sequía en 1848 produjo de manera inmediata una hambruna en Puno debido al fracaso de la cosecha y la epidemia de tifoidea de mediados de la década de 1850 devastó la población del Altiplano con 
altas tasas de mortandad ${ }^{45}$. No pudieron resistir estos desastres. Pero para los años normales podemos aceptar la observación que para principios de la década de 1850 hacía Modesto Basadre subprefecto de Azángaro: “...la indiada de Azángaro con sus cortas chacras y ganados, tenía lo suficiente para cubrir sus escasas necesidades" (Basadre, 1884:144).

\section{V}

Hace cerca de sesenta años José Carlos Mariátegui afirmó tajantemente que con la independencia del Perú "...se inauguró un régimen que, cualesquiera que fuesen sus principios, empeoraba en cierto grado la condición de los indígenas en vez de mejorarla" (Mariátegui, 1974:69). El Amauta llegó a esta conclusión al recorrer un siglo de historia republicana, al final del cual los indígenas habían perdido la mayor parte de sus tierras, habían visto mermarse su autonomía social y cultural y habian continuado siendo tratados como parias en su propio país. Pero es tarea del historiador primero evaluar cada período en cuanto a sus propios méritos, antes de encarar la espinosa cuestión de si las direcciones tomadas pueden ser responsabilizadas por los diferentes problemas que surgirían en los años posteriores. Si los cambios agrarios de la década de 1820 son responsables de las crecientes presiones sobre los campesinos indígenas desde la década de 1860 es una cuestión que debe ser vista de manera distinta de la consideración de sus efectos inmediatos.

Las décadas posteriores a la independencia trajeron una creciente autonomía al campesinado indígena del

45 Perú. Ministerio de Hacienda. Memoria que presenta a la legislatura ordinaria del Perú del año 1849 el oficial mayor del Ministerio de Hacienda encargado de su despacho [José Fabio Melgar] (Lima:Imp. de Eusebio Aranda), 1849, p. 8. Sobre la epidemia de tifoidea de mediados de la década de 1850, ver Jacobsen (mss.:cap. 1). 


\section{NILS JACOBSEN}

Altiplano. Liberados de las medidas coloniales más contradictorias y disruptivas, como la mita de Potosí y los estrictos límites borbones sobre la extensión de las propiedades de comunidades, los campesinos podian consolidar su control sobre la tierra y reconstruir las instituciones comunales en aquellos asentamientos en donde los forasteros habían dejado de ser invasores precarios para convertirse en propietarios. La legislación agraria meramente proporcionaba el espacio legal para esta consolidación y el joven estado central cesó de respaldar los intereses de las élites provinciales como los Borbones lo habian hecho hasta 1780 . Pero el mayor respiro de los campesinos indígenas provino de su propio empuje desde los días de la rebelión de Túpac Amaru y del continuo debilitamiento de las élites provinciales, agobiadas por una crisis comercial semi-secular y una importante recomposición social. Frente a esta crisis, la movilización y la militancia de los campesinos permitió utilizar las contradicciones y la parálisis de las políticas agrarias de los Borbones luego de 1780 y los aspectos igualitarios de las nociones liberales de propiedad, para asegurar su acceso a la tierra.

El liberalismo del siglo XIX en Latinoamérica fue mucho más complejo y ambiguo que lo que la mayoría de los historiadores y los críticos sociales han estado dispuestos a admitir ${ }^{46}$. Mariátegui se equivocó al considerar que el pensamiento y las políticas liberales en el Perú posteriores a la independencia eran "deformadas", que estaban automáticamente vinculadas a, y promovían los intereses de los latifundistas, a quienes él veía como la clase dominante desde el mismo inicio de la República (Mariátegui, 1974:73-5). El liberalismo puede ser parte de una gran variedad de proyectos políticos y puede ser

46 Para la gran diversidad del pensamiento y las políticas liberales en Latinoamérica ver Love y Jacobsen (eds.) (1988). 
usado por diferentes clases sociales y facciones. No era automático que una vertiente autoritaria y exclusiva del liberalismo, como lo fue el discurso preferido de la emergente oligarquía peruana de comerciantes, mineros y agroexportadores, dominara necesariamente la segunda mitad del siglo XIX. Recientes estudios en Bolivia, Mexico $y$ Colombia demuestran cómo dos diferentes nociones liberales sobre la tenencia de la tierra encontraron voceros en la arena política de esos países: una identificada por Mariátegui como todopoderosa e indesafiable -que abogaba por la formación de grandes haciendas, la extinción de la mano de obra arrendataria (colonato) y el trabajo asalariado rural como el modo más eficiente de explotar la tierra. La otra, un discurso social-liberal, que defendía una distribución más amplia de tierras de la Iglesia, la comunidad $y$ las haciendas a pequeñas y medianas familias de agricultores. Ciertos sectores del campesinado apelaron a estas nociones social-liberales para estabilizar y ampliar su acceso a la tierra ${ }^{47}$. Hasta la década de 1850 en varios países latinoamericanos esta noción social-liberal de tenencia de la tierra fue más poderosa que la noción latifundista. En los debates políticos seminales de la década de 1820 en el Perú, la noción social-liberal fue vinculada a las nociones borbónicas sobre la relación entre indígenas $y$ estado. Los bolivarianos y otros liberales defendieron una distribución más amplia de la propiedad debido a que ellos pensaban que ésta podría estimular más la producción que las haciendas "feudales" españolas. Y ellos necesitaban la preservación del campesinado indígena de las comunidades debido a que requerían desesperadamente de la contribución de indígenas como una fuente de ingresos confiable para sus presupuestos deficitarios. Cuando, cerca de cuatro décadas más tarde, Juan Bustamante y sus

47 Para Bolivia ver Langer (1988:59-95); para México, Ducey (mss.), Mallon (1988:7:1-54); y, para Colombia, LeGrand (1986:en especial caps. 2 y 4 ). 
asociados de la Sociedad Amiga de los Indios llevó a cabo el primer intento vacilante y paternalista de un grupo civil para proteger a los indígenas de los abusos y la explotación de las autoridades gamonales y los hacendados, ellos todavía se referían a la legislación de la década de 1820 como el fundamento más fuerte para lograr que el indígena fuera considerado un ciudadano.

Caracterizando su filiación política como "demócrata", ellos distribuyeron una traducción al quechua de los "eternamente gloriosos decretos" de San Martín, Bolivar y Castilla -que convertían al indígena en ciudadano peruano, aboliendo los servicios personales obligatorios $y$, en 1854, la contribución de indígenas. Amonestaron a estos indígenas para que estudiaran estas leyes y reclamaran derechos y protección. Entre estos derechos -como ellos expusieron a sus pupilos indios- estaba aquella de que "nadie puede quitaros lo que poseis individual 0 colectivamente...; todo el que intente quitaros esos objetos al precio que no os convenga, comete un crimen contra vuestra libertad y propiedad contra el cual tenéis derecho para defenderos de todos modos" 48 . Sin embargo, hacia 1867, la mera insistencia en los derechos individuales de los campesinos indígenas, probó una protección en extremo insuficiente frente a los masivos abusos en las tierras comunales.

Pero, las primeras tres décadas de la República, y ciertamente la última parte de la era colonial desde la Gran Rebelión de 1780-83, fueron diferentes. Por cerca de tres cuartos de siglo (desde 1780 hasta principios de la década de 1850), la masiva expansión de haciendas llegó a un alto, los campesinos indígenas recuperaron tierras perdidas en las haciendas recientemente formadas y

48 "El directorio de la Sociedad Amiga de los Indios a sus Amigos [los Indios]", 10 de setiembre de 1867, en Bustamente (comp.) (1867:120-4). 
sus derechos de titulación mejoraron. Ahora la propiedad sobre muchas tierras que se habían encontrado fuera de los angostos confines de las comunidades como lo habían definido los visitadores de tierras de los Borbones, estaba legalmente confirmada. La base de propiedad de tierras de las comunidades campesinas del Altiplano se estabilizó $e$ incluso se amplió durante dos generaciones. Esto se debió tanto a la militancia de los campesinos como a las cambiantes políticas agrarias y la prolongada crisis política, económica y social de las élites provinciales de la región.

En un reciente artículo sobre la población y la etnicidad en el Perú de principios de la República, Paul Gootenberg ha subrayado la remarcable estabilidad de la población indígena del país entre fines del periodo colonial y la década de 1860. La participación indigena en la población total del país se mantuvo en un $62 \%$ entre 1790 y la década de 1860. Por lo tanto, este periodo se encuentra en total contraste tanto con los siglos anteriores del régimen colonial como con el ciclo que comenzaría a partir de 1860, cuando la participación de la población indígena comenzó a declinar (Gootenberg, 1991). Para el Altiplano peruano podemos afirmar con bastante confiabilidad que esta estabilidad se debió en mucho a la consolidación de la base de propiedad de tierras de las comunidades indígenas, al recurso estratégico para la reproducción de su economía doméstica y de su práctica de solidaridad étnica. Esta consolidación no se logró a pesar de las políticas del estado, sino más bien en interacción con ellas. Tuvo implicancias fundamentales para el desarrollo de largo plazo del régimen agrario de la región. Si la formación de haciendas en las tierras de la comunidad hubiera continuado más allá de 1780 al ritmo del siglo anterior, las comunidades campesinas del Altiplano habrian tenido que enfrentar sobre bases considerablemente más débiles la masiva embestida de los gamonales, con un poder renovado durante el ciclo de exportación de lana de fines del siglo XIX y comienzos 
del siglo XX. Su capacidad para sobrevivir a esta ofensiva $y$ mantener estancias familiares incrustadas en las comunidades campesinas como una opción dinámica de la evolución de la cuestión agraria durante el siglo $\mathrm{XX}$, tal vez debe mucho al período de consolidación de la tierra y la reconstrucción de las instituciones comunales de los inicios de la República. La legislación liberal de la década de 1820 creó el escenario para el cambiante significado de la propiedad de la tierra, presagiando el cambio del control comunal sobre las tierras a las estancias familiares individuales. Al estabilizar al campesino indígena, pudo obstruir la victoria absoluta del latifundismo en el Altiplano peruano. 


\section{Bibliografía}

Basadre, Jorge

1968 Historia de la República del Perú, 6ta. ed., 11 tomos (Lima:Ed. Universitaria)

Basadre, Modesto

1884 Riquezas Peruanas. Colección de artículos descriptivos escritos para "La Tribuna" (Lima)

Blum, Jerome

1978 The End of the Old Order in Rural Europe (Princeton:Princeton University Press)

Bustamente, Juan (comp.)

1867 Los Indios del Perú (Lima:Imp. J.M. Monterola)

Cahill, David

1982 "Curas and Social Conflict in the Doctrinas of Cuzco, 1780-1814", Journal of Latin American Studies, 16, pp. 241-276. 
Carrio de la Vandera, Alonso (1782)

1966

Reforma del Perú

(Lima:Universidad Nacional Mayor de San Marcos)

CDIP (Colección Documental de la Independencia del Perú) 1976 (Lima). Varios volúmenes en varios años y por varios editores. Los volúmenes titulados "Los ideólogos" fueron editados por M. Marticorena Estrada.

Coatsworth, John

1974

"Railroads, Landholding and Agrarian Protest in the Early Porfiriato", HAHR 54, pp. 4871

Comité Arquidiocesano del Bicentenario Túpac Amaru (ed.) 1986 Tupac Amaru y la Iglesia, Antología (Lima:Edubanco)

Cornejo B., Jorge

1956 Pumacahua: La revolución del Cuzco de 1814 (Cuzco)

Costa, Joaquín

(1898)

1983

Colectivismo agrario en España, en Obras de Joaquín Acosta, ed. George Cheyne et.al., 10 vols.

(Zaragoza:Guara Editorial)

Choquehuanca, José D.

1833 Ensayo de estadística completa de los ramos económico-politicos de la provincia de Azángaro en el departamento de Puno de la República Peruana del quinquenio contado desde 1825 hasta 1829 inclusive (Lima:Impr.Manuel Corral) 
Dancuart, Emilio y J.M. Rodríguez

1902-26 Anales de la Hacienda Pública del Perú, 24 tomos

Davies, Thomas $\mathrm{M}$.

1974 Indian Integration in Peru: a half century of experience (Lincoln: University of Nebraska Press)

Ducey, Michael

mss. "Peasant Communities in the Huasteca, 18211876", parte de un tesis doctoral en progreso. Universidad de Chicago

Fisher, John

1970 Government and Society in Colonial Peru:The Intendant System, 1784-1814 (Londres:Athlone Press)

Fisher, Lillian E.

1966 The Last Inca Revolt, 1780-1783 (Norman, Oklahoma:University of Oklahoma Press)

Franco Salazar, Pedro

1812 Restauración política-económica y militar de España

Fuente, Manuel A. (ed.)

1859 Memorias de los Virreyes que han gobernado el Perú durante el tiempo del coloniaje español, impresas de orden suprema, 6 vols. (Lima:Librería Central de F. Bailly)

Gonzales Luna, M. Dolores

1977 "La política reformista en los resguardos en el siglo XVIII", Estudios sobre la política 


\section{NILS JACOBSEN}

indigenista española en América, 3 vols. (Valladolid:Seminario de Historia de América, Universidad de Valladolid)

Gonzales N., Moisés

1977 Anatomía del poder en México, 1848-1853 (México:El Colegio de México, Centro de Estudios Históricos, nueva serie, 23

Gootenberg, Paul

1991

"Population and Ethnicity in Early Republican Peru: Some Revisions", Latin American Research Review (próxima publicación)

Harnisch, Hartmut

1968

Die Herrschaft Boitzenburg, Untersuchungen zur Entwicklung der sozialökonomischen Struktur ländlicher Gebiete in der Mark Brandenburg vom 14. bis zum 19. Jahrhundert (Weimar:Hermann Böhlhaus Nachfolger)

Herr, Richard

1958 The Eighteenth Century Revolution in Spain (Princeton:Princeton University Press)

1989

Rural Change and Royal Finances in Spain at the End of the Old Regime (Berkeley:University of California Press)

Hinojosa, Iván

1987

"Población y conflictos campesinos en Coporaque (Espinar), 1770-1784", en A. Flores Galindo (ed.) Comunidades Campesinas: cambios y permanencias. (CES Solidaridad, Chiclayo) 
Hunefeldt, Christine

1989 "Poder y contribuciones: Puno, 1825-1845", Revista Andina

Iwasaki, Fernando

1987 "El pensamiento de Pablo de Olavide y los Ilustrados peruanos", Histórica, XI:2, pp. 133162

Jacobsen, Nils

1982 Landtenure and Society in the Peruvian Altiplano, Azángaro Province: 1770-1920 (Tesis Doctoral, Berkeley:University of California)

mss. (próxima publicación) Mirages of Transition. The Peruvian Altiplano Between Colonialism and the World Market

Jovellanos, Gaspar Melchor de

1976 Prosa Escogida

(Madrid:Novelas y Cuentos)

Juan, Jorge y Santacilia, y Antonio de Ulloa

1826 Noticias secretas de América, 2 vols. Biblioteca de Ayacucho, vols. 31 y 32. (London)

Knight, Alan

1985

"The Mexican Revolution: Bourgeois Nationalist? or just a 'Great Rebellion'?", Bulletin of Latin American Research, 4:2.

Kubler,

1946 "The Quechua in the Colonial World" En Julian Steward, ed, Handbook of South American Indians. Tomo 2. The Andean Civilization. (Washington D.C. Smithsonian Institution) 


\section{NILS JACOBSEN}

Langer, Erick

1988

"El liberalismo y la abolición de la comunidad indigena en el siglo XIX", Historia y Cultura 14 (La Paz)

LeGrand, Catherine

1986 Frontier Expansion and Peasant Protest in Colombia, 1850-1936 (Albuquerque, N.M.: University of New Mexico Press)

Leonhard, Rudolf

1909 Agrarpolitik und Agrarreform in Spanien unter Karl III (Munich y Berlin:Schweitzer)

Lewin, Boleslao

1957 La rebelión de Túpac Amaru y los orígenes de la emancipación americana (Buenos Aires)

Love, Joseph y Nils Jacobsen (eds.)

1988 Guiding the Invisible Hand, Economic Liberalism in Latin American History (Nueva York:Praeger)

Luna, Lizandro

1946 Choquehuanca el Amauta (Lima:Imp. Gráfica Stylo)

Macera, Pablo

1974 Las Plantaciones azucareras en el Perú, 1821-1875 (Lima:Biblioteca Andina)

Mallon, Florencia E.

1988 "Peasants and State Formation in Nineteenth Century Mexico, Morelos 1848-58", Political Power and Social Theory, 7, pp. 1-54

Mariátegui, José C.

"El problema de la tierra", en Siete ensayos 
de interpretación de la realidad peruana, ed. 29 (Lima:Editora Amauta)

Mayer, Enrique

1977 "Tenencia y control comunal de la tierra: Caso de Laraos (Yauyos)", Cuadernos (del Consejo Nacional de la Universidad Peruana) Nos. 24-25, pp. 59-72.

Moscoso, Maximiliano

1965

"Apuntes para la historia de la industria textil en el Cuzco colonial", Revista Universitaria (Cusco) Nos. 122-25

O'Phelan, Scarlett

1985 Rebellions and Revolts in Eighteenth Century Peru and Upper Peru (Colonia: Böhlau Verlag)

1986

"Las reformas fiscales borbónicas y su impacto en la sociedad colonial del Bajo y Alto Perú, en $\mathrm{N}$. Jacobsen y H-J. Puhle, The Economies of Mexico and Peru During the Late Colonial Period, 1760-1810 (Berlin: Colloquium Verlag), pp. 340-356.

Oricaín, Pablo J.

(1790) "Compendio breve de discursos varios sobre 1907 diferentes materias y noticias geográficas comprehensivas a este Obispado del Cuzco", en V.M. Maurtua (ed.) Juicio de limites entre Perú y Bolivia, contestación al alegato de Bolivia, prueba peruana presentada al gobierno argentino por Victor M. Maurtua, abogado y plenipotenciario especial del Perú, 8 tomos (Buenos Aires)

Piel, Jean

Capitalisme Agraire au Perou, Tomo I: 
Originalité de la Societé agraire peruvienne aux XIXe siécle. (Paris:Anthropos)

Ramos Zambrano, Augusto

1982 Puno en la rebelión de Túpac Amaru (Puno:UNTA)

Rodríguez Casado y Florentino Pérez Embid (eds.)

1947 Memoria de Gobierno del Virrey Manuel Amat y Junient (Sevilla:Escuela de Estudios Hispano-Americanos)

Roel, Virgilio

1970 Historia social y económica de la Colonia (Lima)

Sahuarara Tito Atauchi, Raphael J.

1944 Estado del Peru, ed. Francisco A. Loayza (Lima)

Salas P., Gilberto

1957 Monografía sintética de Azángaro (Puno:Ed. "Los Andes")

Salas, Miriam

1986 "Los obrajes huamanguinos y sus interconexiones con otros sectores económicos en el centro-sur peruano a fines del siglo XVIII", en Nils Jacobsen y Hans-Jurgen Puhle (eds.), The Economies of Mexico and Peru in the Late Colonial Period, 1760-1810 (Berlin: Colloquium Verlag), pp. 203-232.

Sallnow, Michael J.

1983

"Manorial Labour and Religious Ideology in the Central Andes, a Working Hypothesis", Bulletin of Latin American Research, 2:2, pp. 39-56 
Santamaría, Daniel

1979

"La estructura agraria del Alto Perú a fines del siglo XVIII; un análisis de tres regiones maiceras del partido de Larecaja en 1795", Desarrollo Económico, № 72, pp. 579-595

Sarrailh, Jean

1957 La España Ilustrada de la segunda mitad del siglo XVIII (México:Fondo de Cultura Económica)

Sivirichi, Atilio

1946 Derecho indígena peruano: proyecto de código indígena (Lima:Ed. Kuntur)

Spalding, Karen

1973 . De Indio a Campesino

(Lima:Instituto de Estudios Peruanos)

1975 "Hacienda-Village Relations in Andean Society to 1830", Latin American Perspectives, 2, pp. $107-122$

$1984 \quad$ Huarochirí

(Stanford:Stanford University Press)

Stern, Steve (ed.)

1987 Resistance, Rebellion and Conciousness in the Andean Peasant World, Eighteenth to Twentieth Centuries (Madison:University of Wisconsin Press)

Tandeter, Enrique

1980

"Trabajo forzado y trabajo libre en el Potosí tardío", Estudios CEDES (Buenos Aires)

Tutino, John

1986 From Insurrection to Revolution, Social 
NILS JACOBSEN

Bases of Agrarian Violence, 1750-1940 (Princeton, N.J.:Princeton University Press)

Van Young, Eric

1986 "The Age of Paradox: Mexican Agriculture at the End of the Colonial Period, 1760-1810", en N. Jacobsen y H-J. Puhle (eds.) The Economies of Mexico and Peru in the Late Colonial Period, 1760-1810 (Berlin:Colloquium Verlag)

Vassberg, David

1984 Land and Society in Golden Age Castile (Cambridge:Cambridge University Press)

Valdez de la Torre,

1921 Evolución de las comunidades de indigenas (Lima:Euforión)

Vega, Juan J.

1969 José Gabriel Túpac Amaru (Lima:Ed. Universo)

Wightman, Ann M.

1990 Indigenous Migration and Social Change. The Forasteros of Cuzco, 1570-1720 (Durham, N.C.:Duke University Press) 